\title{
Determination of the thermoelectric properties of a skutterudite-based device at practical operating temperatures by impedance spectroscopy
}

Chung-Yul Yoo a, ${ }^{\mathrm{a},}$, Changho Yeon ${ }^{\mathrm{a}}$, Younghwan Jina, Yeongseon Kimª, Jinseop Song ${ }^{\mathrm{a}}$, Hana Yoon $^{\mathrm{a}}$, Sang Hyun Park ${ }^{\mathrm{a}}$, Braulio Beltrán-Pitarch ${ }^{\mathrm{b}}$, Jorge García-Cañadas ${ }^{\mathrm{b}}, \mathrm{Gao} \mathrm{Min}^{\mathrm{c}}$

${ }^{a}$ Korea Institute of Energy Research, 152 Gajeong-ro, Yuseong-gu, Daejeon 34129, Republic of Korea

${ }^{\mathrm{b}}$ Department of Industrial Systems Engineering and Design, Universitat Jaume I, Campus del Riu Sec, 12071 Castellón, Spain

${ }^{\mathrm{c} S}$ Shool of Engineering, Cardiff University, Cardiff CF24 3AA, United Kingdom

* To whom all correspondence should be addressed. Tel: +82-42-860-3083, Fax:

+82-42-860-3133, E-mail: cyoo@kier.re.kr (Chung-Yul Yoo) 


\section{Abstract}

Skutterudite-based thermoelectric materials are promising candidates for waste heat recovery applications at intermediate temperatures $\left(300-500{ }^{\circ} \mathrm{C}\right)$ owing to their high dimensionless figure of merit and power factor. Recently, several researchers have reported the high performance of skutterudite-based thermoelectric devices obtained by optimizing the crystal structure and microstructure of skutterudite materials and developing metallization layers for device fabrication. Despite extensive research efforts toward maximizing the power density and thermoelectric conversion efficiency of skutterudite-based devices, the thermoelectric properties of such devices after fabrication remain largely unknown. Here, we systematically investigated the factors that affect the thermoelectric properties of skutterudite-based devices within the range of practical operating temperatures $\left(23-450^{\circ} \mathrm{C}\right)$. We successfully prepared a two-couple skutterudite-based device with titanium metallization layers on both sides of the thermoelectric legs and characterized it using scanning and transmission electron microscopy and specific contact resistance measurements. Impedance spectroscopy measurements of the two-couple skutterudite-based device revealed the figure of merit of the device and enabled the extraction of three key thermoelectric parameters (Seebeck coefficient, thermal conductivity, and electrical conductivity). The impedance spectra and extracted parameters depended strongly on the measurement temperature and were mainly attributable to the thermoelectric properties of skutterudite materials. These observations demonstrate the interplay between the properties of thermoelectric materials and devices and can aid in directing future research on thermoelectric device fabrication.

Keywords: thermoelectric device; skutterudite; figure of merit; impedance spectroscopy; thermoelectric property 


\section{Introduction}

Owing to the increasing demand for waste heat harvesting technologies, significant advances have been made over the past few decades toward the development of highly efficient bismuth telluride [1-3], germanium telluride [4,5], lead telluride [6,7], skutterudite (SKD) [812], half-Heusler [9,13-15], and oxide [9,14] based materials as well as bismuth telluride [16,17], lead telluride [18,19], SKD [20-25], half-Heusler [26-28] based thermoelectric devices. Thermoelectric devices due to their solid-state nature have the advantage of no moving parts and consequently offer compactness, quietness, and high reliability. The thermoelectric conversion efficiency of materials and devices is mainly determined by the figure of merit, $Z T=T \sigma S^{2} / \lambda$, where $T$ is the absolute temperature, $\sigma$ the electrical conductivity, $S$ the Seebeck coefficient, and $\lambda$ the thermal conductivity. To date, most efforts have focused on enhancing the $Z T$ values of thermoelectric materials by optimizing the chemical composition $[6,8,10]$ and microstructure $[13,15]$. However, it is a significant challenge to determine the thermoelectric properties of devices because of their complex structures, which comprise arrays of thermoelectric legs, metallization layers, electrodes, and insulating plates.

To characterize thermoelectric devices, Harman's method and power output measurements have been widely used to evaluate the $Z T$ values and thermoelectric power, respectively, but additional extensive measurements are necessary to determine the three key parameters $(\sigma, S$, and $\lambda)$. Recently, several studies have demonstrated that impedance spectroscopy can be used to determine the $Z T$ values of thermoelectric bismuth telluride [29] and SKD [30,31] materials as well as bismuth telluride [32-38] and SKD [39,40] based devices. In a typical galvanostatic impedance spectroscopy measurement, a sinusoidal current perturbation 
drives the thermoelectric system slightly out of temperature equilibrium (appearance of a temperature gradient), inducing reorganization of the carriers owing to the Peltier effect, which allows the Seebeck voltage to be measured as a function of frequency. The impedance value at a given frequency is obtained from the ratio of the measured voltage amplitude to the applied current amplitude together with the phase angle difference. This protocol is repeated over several decades of frequency to obtain the impedance spectrum. $Z T$ and the three key parameters $(\sigma, S$, and $\lambda$ ) can then be extracted using suitable mathematical models (equivalent circuits) [29,37].

Most investigations using impedance spectroscopy for the characterization of bismuth telluride $[29,32,34,35,38]$ and SKD $[39,40]$ based thermoelectric devices have been performed at ambient temperature, with only a few studies reporting the properties of bismuth telluride based devices at operating temperatures up to $150{ }^{\circ} \mathrm{C}[33,37]$. In this work, we employed impedance spectroscopy to elucidate the thermoelectric properties of an in-house-fabricated two-couple SKD-based device within the range of practical operating temperatures $\left(23-450{ }^{\circ} \mathrm{C}\right)$ with the help of state-of-the-art mathematical models along with electrical, thermal, and microstructural characterization. To the best of our knowledge, this is the first detailed and systematic investigation of the factors that affect the properties of SKD-based thermoelectric devices.

\section{Materials and methods}

2.1 Materials, device fabrication, and electrical/thermal property measurements

Commercial SKD powders (composition $\mathrm{DD}_{y} \mathrm{Fe}_{3} \mathrm{CoSb}_{12}$ for p-type $\mathrm{SKD}$ and $(\mathrm{Mm}, \mathrm{Sm})_{y} \mathrm{Co}_{4} \mathrm{Sb}_{12}$ for n-type $\mathrm{SKD}$, where DD and Mm stand for didymium and mischmetal, respectively) were provided by Treibacher Industrie AG [24,41]. The as-received SKD powders 
( $3 \mathrm{~g}$ ) were sandwiched between two Ti foils (50 $\mu \mathrm{m}$ thickness, Alfa Aesar, 99.6\%) and then coldpressed using a graphite die with a diameter of $12 \mathrm{~mm}$. SKD discs metallized on both sides with $\mathrm{Ti}$ (Ti/SKD/Ti joints) were prepared by spark plasma sintering (SPS) (SPS-211LX, Fuji Electronic Industrial Co., Ltd.) at $620^{\circ} \mathrm{C}$ for p-type SKD and $650{ }^{\circ} \mathrm{C}$ for n-type SKD at $50 \mathrm{MPa}$ under $1.3 \times 10^{-4} \mathrm{kPa}$. To fabricate a two-couple device, cube-shaped legs with sizes of $4 \times 4 \times 4$ $\mathrm{mm}^{3}$ were cut from the sintered discs and polished using $1 \mu \mathrm{m}$ grade alumina abrasive. The two p-type and n-type SKD legs were integrated in series with $\mathrm{Cu}$ electrodes on an $\mathrm{Al}_{2} \mathrm{O}_{3}$ substrate (thickness $0.76 \mathrm{~mm}$ ) using an Incusil-series brazing alloy on both sides. Conductive Ag paste was used to connect four copper wires to the SKD device, and then the joint was covered using graphite paste to ensure connection between the SKD device and the wires, as shown in Fig. 1 (a). Fig. 1 (b) shows that similar impedance spectra are obtained for the wireless SKD device suspended in a vacuum chamber and the wired SKD device in a heating block with an insulating cloth. It can been seen from Fig. 1 (b) that the resistance of the wires in the thermoelectric device is less than $10 \mu \Omega$; hence, the wiring, insulating cloth, and heating block have insignificant effects on the impedance spectroscopy measurements. 


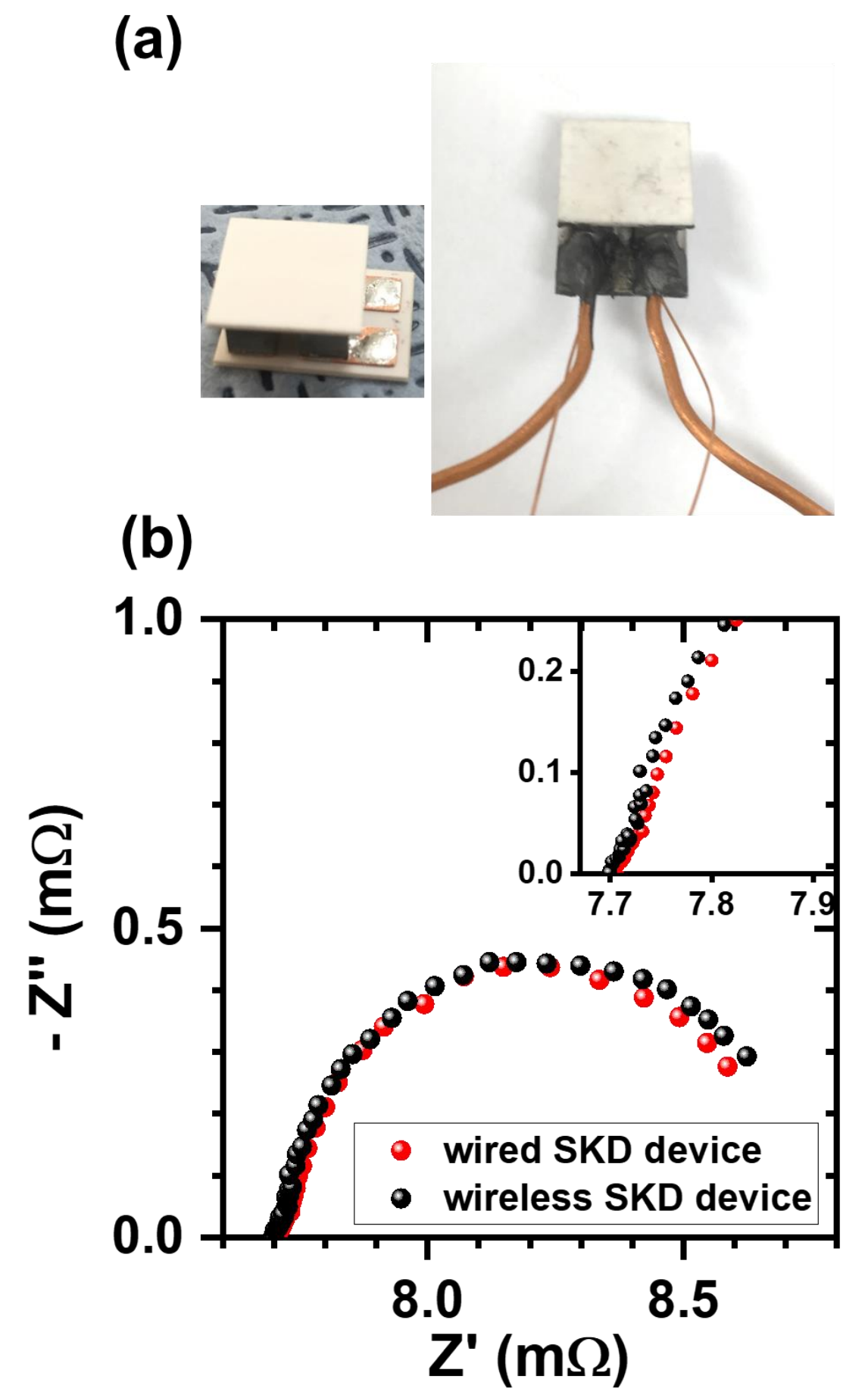

Fig. 1 (a) Photographs of the wireless and wired two-couple SKD device. (b) Impedance spectra of the wireless SKD device suspended in a vacuum chamber and the wired SKD device in a heating block with an insulating cloth. 
The interface between Ti and SKD (Ti/SKD) was examined using scanning electron microscopy (SEM) together with energy-dispersive X-ray spectroscopy (EDS) (JEOL JSM7000F). The details of the Ti/SKD interfacial structure were investigated by high-angle annular dark-field scanning transmission electron microscopy (HAADF-STEM) (JEOL JEM-2100F and JEM-ARM200) together with EDS and selected-area electron diffraction (SAED). The lamellar specimens were prepared using a focused ion beams (FIB) (Helios NanoLab). The SAED patterns were analyzed using the CrysTBox software [42]. The specific contact resistance at the Ti/SKD interface was evaluated using an in-house electrical contact resistivity apparatus at $23{ }^{\circ} \mathrm{C}$ [43]. Laser flash analysis (LFA 447, Netzsch) was employed to measure the thermal diffusivity of the SKD materials and $\mathrm{Al}_{2} \mathrm{O}_{3}$ substrate. The thermal conductivity was obtained as $\lambda_{\mathrm{TE}}=$ $D^{\cdot} C_{\mathrm{p}} \cdot \rho$, where $D$ is the thermal diffusivity, $C_{\mathrm{p}}$ is the specific heat, and $\rho$ is the mass density of the specimen. The temperature-dependent $C_{\mathrm{p}}$ values were measured directly using differential scanning calorimetry (DSC 214 Polyma, Netzsch). The $\rho$ values were determined from mass and volume measurements for each specimen.

\subsection{Impedance spectroscopy measurements and data analysis}

The SKD device was suspended in a vacuum chamber $(0.13 \mathrm{kPa})$ and placed in a copper heating block. To avoid direct contact between the thermoelectric device and the copper heating block, the interface was insulated using multiple layers of ceramic insulation cloth (RS-Cloth, Zircar Inc.). A schematic of the experimental setup is shown in Fig. S1 in the Supplementary Material. The impedance spectroscopy data for the SKD device were collected over the temperature range of $23-450{ }^{\circ} \mathrm{C}$ in the frequency range of $10^{-2}$ to $10^{3} \mathrm{~Hz}$ using a 
potentiostat/galvanostat (Autolab PGSTAT302N, Metrohm) connected to a 10 A current booster with a sine-wave oscillation current in a four-probe configuration. In a previous study by our group [40], it was found that the oscillation current value corresponding to the Peltier heat power density of $1000 \mathrm{~W} \cdot \mathrm{m}^{-2}$ for an SKD two-couple thermoelectric device was in good agreement with the results of Beltrán-Pitarch et al. [30]. As the $S$ values of SKD materials increase with temperature, the Peltier power density was employed to optimize the oscillation current amplitude value at each temperature. The optimized current amplitude $(I)$ at each measurement temperature was calculated using $I=P P\left(A /\left(S_{\text {ave }} T\right)\right)$, where $P P$ is the Peltier power density $\left(1000 \mathrm{~W} \cdot \mathrm{m}^{-2}\right), S_{\text {ave }}$ is the average Seebeck coefficient for p-type and n-type SKD at each temperature [24], $T$ is the absolute temperature, and $A$ is the area of the thermoelectric legs. At each measurement temperature, the isothermal condition was assumed for the impedance spectroscopy measurements when there was no change in the recorded impedance spectra.

The obtained impedance spectra were analyzed using both i) ideal [29] and ii) comprehensive [37] models to characterize the thermoelectric device properties. The ideal model is derived from a one-dimensional heat equation, as described by García-Cañadas and Min [29] under the assumption of adiabatic conditions in all surfaces. It can be written as,

$$
Z(\mathrm{j} \omega)=R_{\Omega}+\left(\frac{1}{Z_{\mathrm{WCT}}(\mathrm{j} \omega)^{-1}+Z_{\mathrm{Wa}}(\mathrm{j} \omega)^{-1}}\right)
$$

where $R_{\Omega}$ is the total ohmic resistance, $j=(-1)^{0.5}$, and $\omega$ is the angular frequency. $Z_{\mathrm{WCT}}$ and $Z_{\mathrm{Wa}}$ are a constant temperature Warburg element and an adiabatic Warburg element, respectively, which are defined as: 


$$
\begin{gathered}
Z_{\mathrm{WCT}}(\mathrm{j} \omega)=R_{\mathrm{TE}}\left(\frac{\mathrm{j} \omega}{\omega_{\mathrm{TE}}}\right)^{-0.5} \tanh \left[\left(\frac{\mathrm{j} \omega}{\omega_{\mathrm{TE}}}\right)^{0.5}\right], \\
Z_{\mathrm{Wa}}(\mathrm{j} \omega)=R_{\mathrm{C}}\left(\frac{\mathrm{j} \omega}{\omega_{\mathrm{C}}}\right)^{-0.5} \operatorname{coth}\left[\left(\frac{\mathrm{j} \omega}{\omega_{\mathrm{C}}}\right)^{0.5}\right],
\end{gathered}
$$

where $R_{\mathrm{TE}}=2 N S^{2} T L /\left(\lambda_{\mathrm{TE}} A\right)$ is the thermoelectric resistance and $R_{\mathrm{C}}=4 N S^{2} T L_{\mathrm{C}} /\left(\lambda_{\mathrm{C}} A\right)$ is the thermoelectric resistance induced by the ceramic layer. In addition, $\omega_{\mathrm{TE}}=\alpha_{\mathrm{TE}} /(L / 2)^{2}$ and $\omega_{C}=$ $\alpha_{\mathrm{C}} / L_{\mathrm{C}}{ }^{2}$ are the characteristic angular frequencies of thermal diffusion for the thermoelectric and ceramic materials, respectively, where $N$ is the number of thermoelectric couples, $T$ is the absolute temperature, $\lambda_{\mathrm{TE}}$ and $\lambda_{\mathrm{C}}$ are the thermal conductivities of the thermoelectric element and insulating ceramic plate, respectively, $L$ and $L_{\mathrm{C}}$ are the lengths of the thermoelectric element and ceramic plate, respectively, and $\alpha_{\mathrm{TE}}$ and $\alpha_{\mathrm{C}}$ are the thermal diffusivities of the thermoelectric element and ceramic plate, respectively.

The $\sigma, S, \lambda_{\mathrm{TE}}$, and $Z T$ values can be calculated using the following expressions:

$$
\begin{gathered}
\sigma=2 N \frac{L}{R_{\Omega} \mathrm{A}}, \\
S=\sqrt{\frac{R_{\mathrm{C}} \lambda_{\mathrm{C}} \mathrm{A}}{4 N T L_{\mathrm{C}}}} \\
\lambda_{\mathrm{TE}}=\frac{2 N S^{2} T L}{R_{\mathrm{TE}} \mathrm{A}}, \\
Z T=\frac{S^{2} \sigma}{\lambda_{\mathrm{TE}}} T=\frac{R_{T E}}{R_{\Omega}},
\end{gathered}
$$

where the parasitic contributions to the ohmic resistance (wires, copper strips, and electrical contacts between them) are neglected. 
To estimate the thermoelectric parameters accurately, a more comprehensive model can be derived from a corrected one-dimensional heat equation including thermal convection, radiation, and spreading-constriction thermal impedance corrections, as described by Mesalam et al. [37]:

$$
Z_{\mathrm{m}}(\mathrm{j} \omega)=R_{\Omega}+\left(\frac{1}{Z_{\mathrm{WTE}, \mathrm{m}}(\mathrm{j} \omega)^{-1}+Z_{\mathrm{Wa}, \mathrm{m}}(\mathrm{j} \omega)^{-1}}\right)
$$

where the modified constant temperature Warburg element and adiabatic Warburg take the following forms:

$$
\begin{aligned}
Z_{\mathrm{WTE}, \mathrm{m}}(\mathrm{j} \omega) & =R_{\mathrm{TE}}\left(\frac{h_{1} L^{2}}{2 \lambda_{\mathrm{TE}} r_{0}}+\frac{\mathrm{j} \omega}{\omega_{\mathrm{TE}}}\right)^{-0.5} \tanh \left[\left(\frac{h_{1} L^{2}}{2 \lambda_{\mathrm{TE}} r_{0}}+\frac{\mathrm{j} \omega}{\omega_{\mathrm{TE}}}\right)^{0.5}\right] \\
Z_{\mathrm{Wa}, \mathrm{m}}(\mathrm{j} \omega)=\{ & \left(\frac{4 N S^{2} T}{h_{2} A}\left(\frac{\eta}{1-\eta}\right)\right)^{-1} \\
& +\left[\frac{4 N S^{2} T}{Y_{\mathrm{SC}} A}\right. \\
& +\left(\left(\frac{4 N S^{2} T}{h_{3} A}\right)^{-1}+\left(\eta R_{\mathrm{C}}\left(\frac{\mathrm{j} \omega}{\omega_{\mathrm{C}}}\right)^{-0.5} \operatorname{coth}\left[\left(\frac{\mathrm{j} \omega}{\omega_{\mathrm{C}}}\right)^{0.5}\right]\right)^{-1}\right)^{-1} \\
& +\left(\left(\eta R_{\mathrm{C}}\left(\frac{\mathrm{j} \omega}{\omega_{\mathrm{C}}}\right)^{-0.5} \tanh \left[\left(\frac{\mathrm{j} \omega}{\omega_{\mathrm{C}}}\right)^{0.5}\right]\right)^{-1}\right. \\
& \left.\left.\left.+\left(\frac{4 N S^{2} T L_{\mathrm{C}}^{2} h_{3} \omega_{\mathrm{C}}}{\mathrm{j} \omega A \lambda_{\mathrm{C}}^{2} \eta^{2}}\right)^{-1}\right)^{-1}\right]^{-1}\right\}^{-1}
\end{aligned}
$$


where $\eta$ is the filling factor $(0.66), r_{0}$ is the thermoelectric leg radius $(\sqrt{A / \pi}), Y_{\mathrm{SC}}$ is the spreading-constriction impedance between the $\mathrm{SKD}$ legs and the $\mathrm{Al}_{2} \mathrm{O}_{3}$ plate (given by

$$
\frac{1}{Y_{\mathrm{SC}}}=\frac{4 L_{\mathrm{C}}}{\lambda_{\mathrm{C}}} \sum_{n=1}^{\infty}\left[\frac{\left.J_{1}^{2}\left(\delta_{n} \eta^{0.5}\right) \operatorname{coth}\left(\eta \delta_{n}{ }^{2}\left(\frac{\pi L_{\mathrm{C}}^{2}}{A}\right)+\frac{\mathrm{j} \omega}{\omega_{\mathrm{C}}}\right)^{0.5}\right)}{\delta_{n}{ }^{2} J_{0}^{2} \delta_{n}\left(\eta \delta_{n}{ }^{2}\left(\frac{\pi L_{\mathrm{C}}^{2}}{A}\right)+\frac{\mathrm{j} \omega}{\omega_{\mathrm{C}}}\right)^{0.5}}\right],
$$

in which $J_{0}$ and $J_{1}$ are the zero- and first-order Bessel functions of the first kind, and $\delta_{n}$ is the $n$th zero root of $\left.J_{1}\right), \sigma_{\mathrm{B}}$ is the Stefan-Boltzmann constant $\left(5.67 \times 10^{-8} \mathrm{~kg} \cdot \mathrm{s}^{-3} \cdot \mathrm{K}^{-4}\right), \varepsilon$ is the emissivity (0.9 for SKD [44] and 0.5 for $\left.\mathrm{Al}_{2} \mathrm{O}_{3}[37]\right), h_{1}=4 \sigma_{\mathrm{B}} \varepsilon_{\mathrm{TE}} T^{3}$ is the radiative heat loss of the thermoelectric legs, $h_{2}=4 \sigma_{\mathrm{B}} \varepsilon_{\mathrm{C}} T^{3}$ is the radiative heat loss at the internal surface of the $\mathrm{Al}_{2} \mathrm{O}_{3}$ plate, and $h_{3}=h_{\mathrm{C}}+4 \sigma_{\mathrm{B}} \varepsilon_{\mathrm{C}} T^{3}$ is the radiative and convective heat loss at the external surface of the $\mathrm{Al}_{2} \mathrm{O}_{3}$ plate (where $h_{\mathrm{C}}$ is the convective heat transfer coefficient at the external surface of the ceramic plates. The $\sigma, S, \lambda_{\mathrm{TE}}$, and $Z T$ values were calculated using Eq. (4)-(7). For both the models, the complex nonlinear least-squares analysis of the impedance spectra was performed with MATLAB using five free fitting variables $\left(R_{\Omega}, R_{\mathrm{C}}, R_{\mathrm{TE}}, \omega_{\mathrm{C}}\right.$, and $\left.\omega_{\mathrm{TE}}\right)$ simultaneously by minimizing a functional that measures the discrepancies between the obtained data and the models. The fittings of the experimental data to the above equations were carried out using the built-in function "Isqcurvefit" from the MATLAB Optimization Toolbox with a trust-region reflective algorithm and convergence criteria (80,000 iterations, tolerance $\left.10^{-15}\right)$.

\section{Results and discussion}

The Ti metallization layer has been found to exhibit a low specific contact resistance and excellent bonding characteristics for SKD-based thermoelectric materials $\left(\mathrm{CoSb}_{3}\right.$ [45-47], 
$\mathrm{Yb}_{0.6} \mathrm{Co}_{4} \mathrm{Sb}_{12}$ [48], and $\mathrm{Ce}_{\mathrm{y}} \mathrm{Fe}_{\mathrm{x}} \mathrm{Co}_{4-\mathrm{x}} \mathrm{Sb}_{12}$ [49]). Fig. 2 shows the cross-sectional SEM images and EDS elemental line-scan results for the Ti/SKD interfaces, together with the specific contact resistance between Ti and SKD. As shown in the SEM images in Fig. 2a and c, the metallization layers are tightly bonded to the SKD leg surfaces. However, the EDS line-scan results indicate that some intermetallic phases are formed during SPS because of the interfacial reaction at the Ti/SKD interface. To perform a more detailed analysis, HAADF-STEM images and SAED patterns were obtained from the FIB lamella prepared from the Ti/SKD interface. The distinct areas of the HAADF-STEM images obtained by contrast difference are shown in Fig. 3a and $g$ for $\mathrm{p}$-type and n-type SKD, respectively. The SAED patterns along the zone axes of the corresponding areas are shown in Fig. $3 \mathrm{~b}-\mathrm{f}$ and $\mathrm{h}-\mathrm{l}$ and include representative Miller indices. Two intermetallic phases with different crystal structures are observed for Ti/p-type SKD, namely, hexagonal TiSb near Ti and orthorhombic (FeCo)Sb $\mathrm{Sb}_{2}$ near p-type SKD. In contrast, three intermetallic phases are observed for Ti/n-type SKD, namely, hexagonal TiSb near Ti, and orthorhombic $\mathrm{CoSb}_{2}$ and cubic TiCoSb near n-type SKD. These observations are consistent with the SEM-EDS results. Moreover, the observation of intermetallic compounds at the Ti/SKD interface is in good agreement with the results reported in the literature $[45,46,48-50]$. Detailed indexing of the SAED patterns is provided in the Supplementary Material (Fig. S2 and S3). According to previous reports $[45,46,48,49]$, the formation and growth of TiSb and TiCoSb phases are further accelerated upon heat treatment at temperatures above $500{ }^{\circ} \mathrm{C}$, resulting in an increase in the electrical contact resistance and fracture failure of Ti/SKD interfaces. Hence, in this study, the impedance spectroscopy measurements of the SKD device were only performed up to $450{ }^{\circ} \mathrm{C}$ to avoid the formation of further TiSb and TiCoSb phases. Even though there is an interfacial reaction between $\mathrm{Ti}$ and $\mathrm{SKD}$, the specific contact resistivity at the Ti/SKD interface 
was very low $\left(3.06 \mu \Omega \cdot \mathrm{cm}^{2}\right.$ for p-type SKD and $4.37 \mu \Omega \cdot \mathrm{cm}^{2}$ for n-type SKD), in agreement with previous studies $[48,49]$.
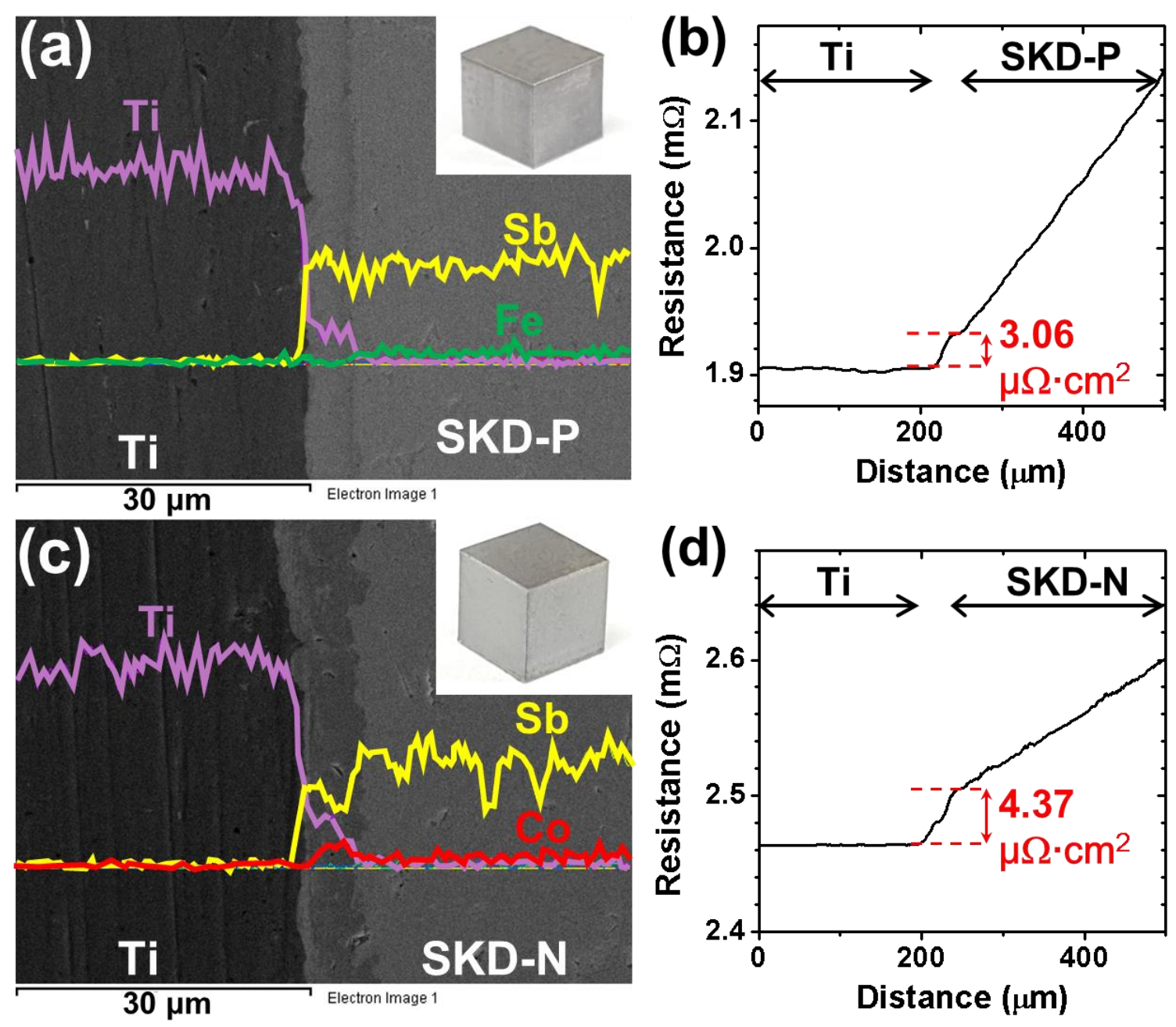

Fig. 2 Scanning electron microscopy (SEM) images with energy-dispersive X-ray spectroscopy (EDS) line scanning profiles (left) and electrical contact resistivity (right) of Ti metallized (a, b) p-type skutterudite (SKD) joints and (c, d) n-type SKD joints. Insets: photographs of the Ti metallized SKD thermoelectric legs. 

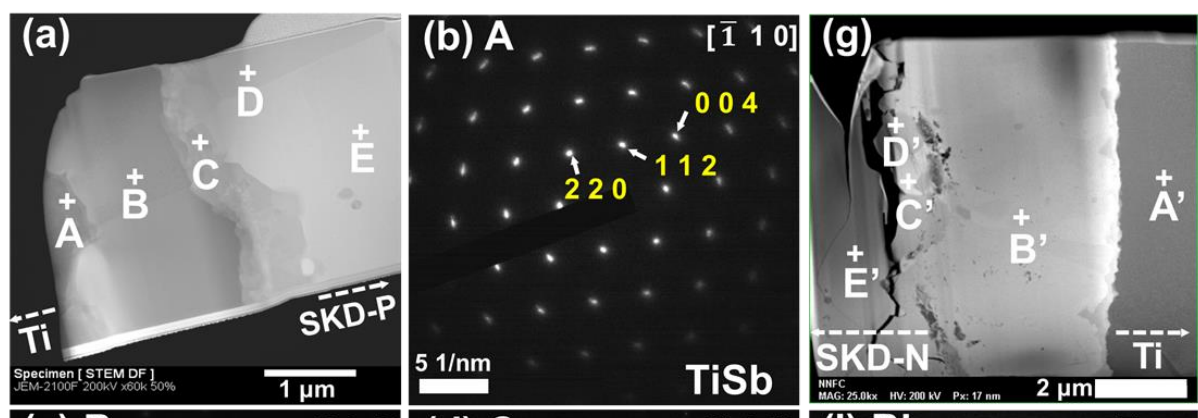

(h) $A^{\prime}$

[1 100$]$
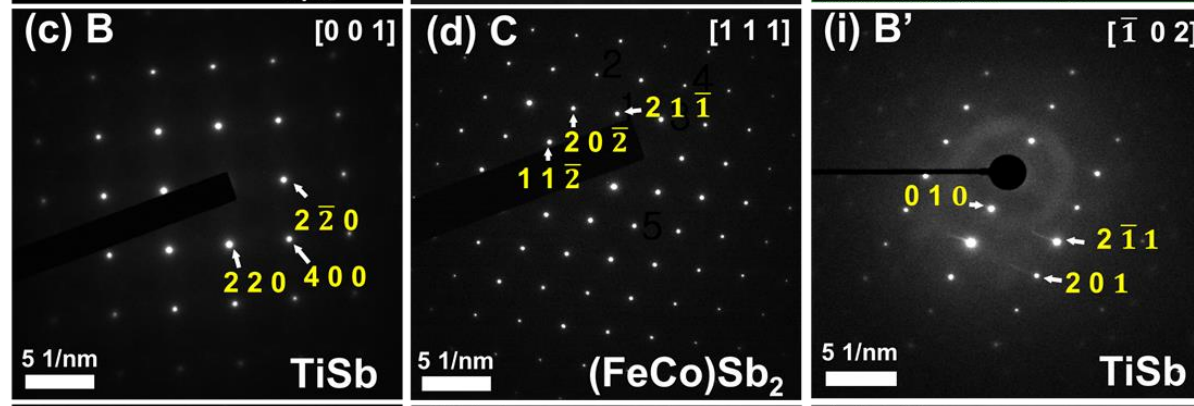

$51 / \mathrm{nm}$

$\mathrm{Ti}$
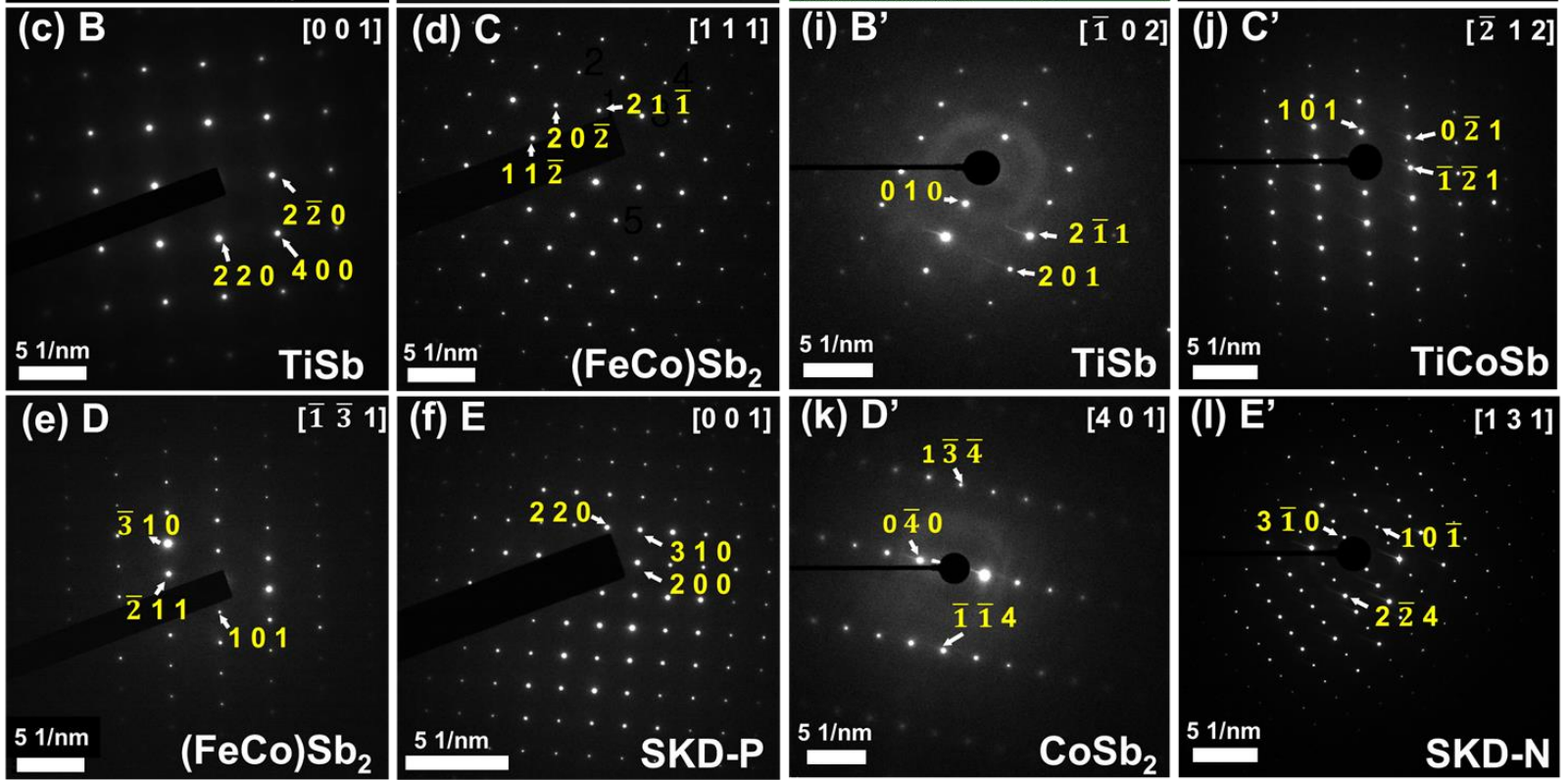

$310:$
$\overline{2} 11$

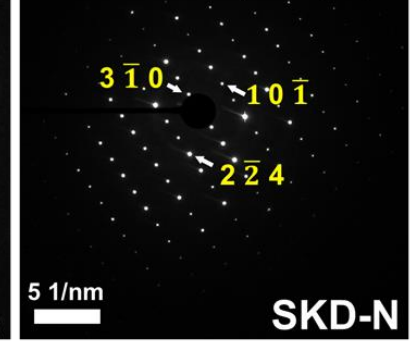

Fig. 3 High-angle annular dark-field scanning transmission electron microscopy (HAADF-

STEM) images at the Ti/SKD interface and selected-area electron diffraction (SAED) patterns of the corresponding regions in the HAADF-STEM images along the $[u v w]$ zone axis for (a-f) ptype SKD and (g-1) n-type SKD. 
Prior to the detailed analysis, Kramers-Kronig (KK) transformation tests were performed to evaluate the impedance spectra of the SKD device. This method provides a very effective way to assess the consistency of spectra and to exclude spectra containing non-steady-state behavior in the field of thermoelectrics [40], solid state ionics [51,52], and electrochemistry [53]. As shown in Fig. 4, to validate the measurements, residual plots for the deviations of the real $\left(\Delta Z_{\mathrm{re}}(\omega)\right)$ and imaginary $\left(\Delta Z_{\mathrm{im}}(\omega)\right)$ parts can be obtained from the differences between the experimental impedance data $\left(Z_{\mathrm{re}}\right.$ and $\left.Z_{\mathrm{im}}\right)$ and the $\mathrm{KK}$ transformation results $\left(Z_{\mathrm{re}, \mathrm{KK}}\right.$ and $\left.Z_{\mathrm{im}, \mathrm{KK}}\right)$. The impedance spectra at frequencies higher than $0.2 \mathrm{~Hz}$ are mainly due to the contacts (electrical contacts and $\mathrm{Al}_{2} \mathrm{O}_{3}$ plates); hence, the observation of residual errors close to zero at frequencies higher than $0.2 \mathrm{~Hz}$ indicates that the in-house-fabricated two-couple SKD device has excellent contact characteristics. At frequencies lower than $0.2 \mathrm{~Hz}$, the residual errors are higher (up to $0.4 \%$ ) and increase slightly with temperature. The impedance spectra at frequencies lower than $0.2 \mathrm{~Hz}$ are related to the Seebeck voltage of both p-type and n-type SKD thermoelectric materials. The high residual errors at frequencies lower than $0.2 \mathrm{~Hz}$ could originate from the heat loss of the thermoelectric legs upon Peltier heating/cooling during impedance spectroscopy measurements. Nevertheless, as the residual errors are less than $\pm 0.5 \%$ over the entire frequency range $[40,53]$, all of the impedance spectra of the SKD device are a response to the current oscillation applied under the steady-state conditions. Therefore, all of the impedance spectra are KK-transformable and can be further analyzed by nonlinear least-squares analysis to evaluate the thermoelectric properties of the two-couple SKD device. 

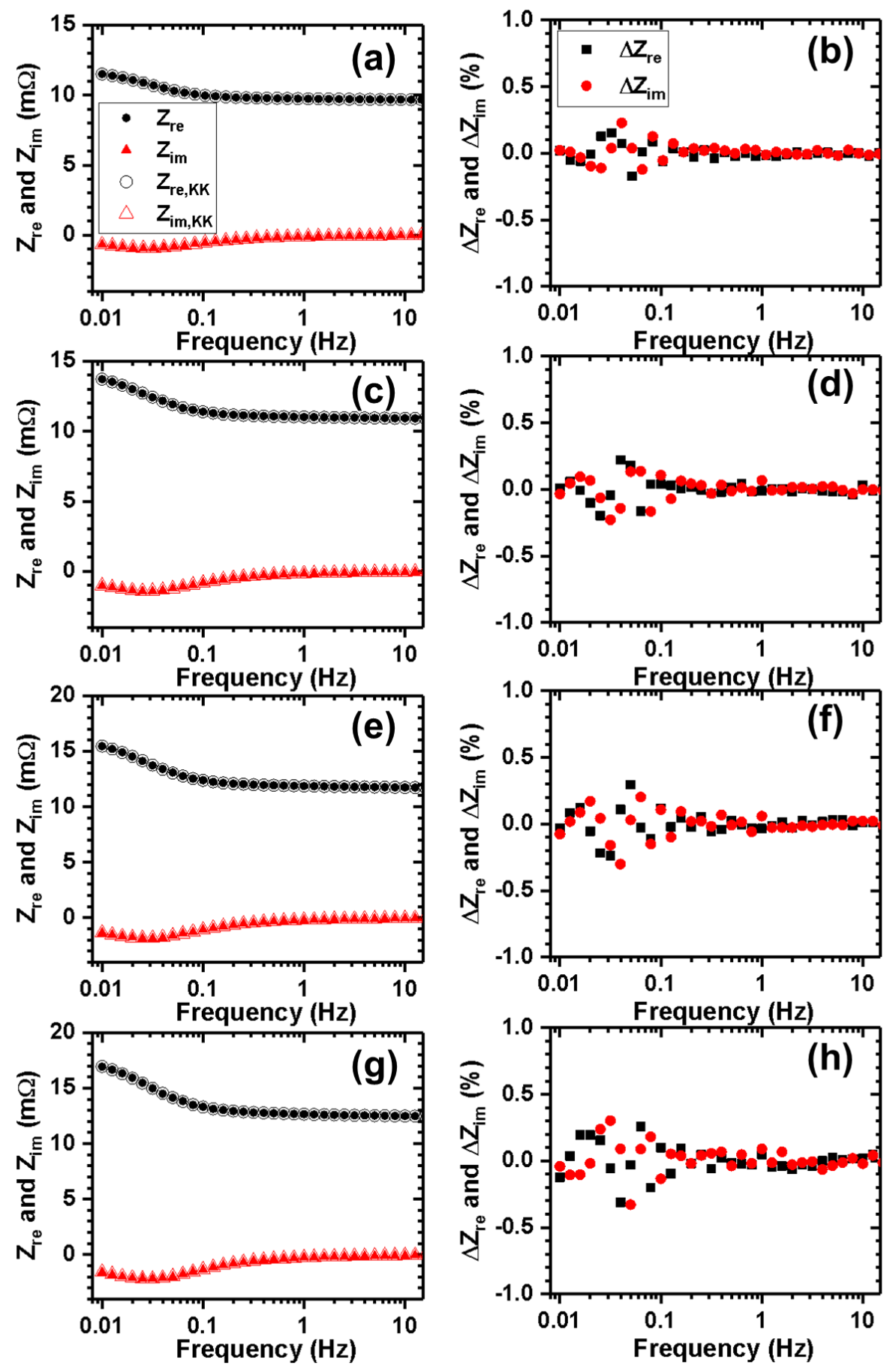

Fig. 4 Kramers-Kronig (KK) transformation results (empty symbols) of impedance spectra (filled symbols) (left) and residual plots (right) for the two-couple SKD device at (a, b) $150{ }^{\circ} \mathrm{C}$, (c, d) $250{ }^{\circ} \mathrm{C}$, (e, f) $350{ }^{\circ} \mathrm{C}$, and (g, h) $450{ }^{\circ} \mathrm{C}$. 
Fig. 5 shows the Nyquist plots of the impedance spectra for the two-couple SKD device over the temperature range $23-450{ }^{\circ} \mathrm{C}$. The high-frequency real axis intercept of each impedance spectrum corresponds to the ohmic electrical resistance of the SKD device, which increases with temperature, mainly because of the increase in the electrical resistance of the SKD thermoelectric materials. From this point towards lower frequencies, a linear trend overlapped with an impedance arc is observed due to the response of the $\mathrm{Al}_{2} \mathrm{O}_{3}$ insulating plates and thermoelectric materials integrated in the SKD device upon application of current perturbation. The contribution of the arc increases with temperature, mainly owing to the increase in $Z T \cdot \sigma^{-1}$ of the SKD thermoelectric materials with temperature. 


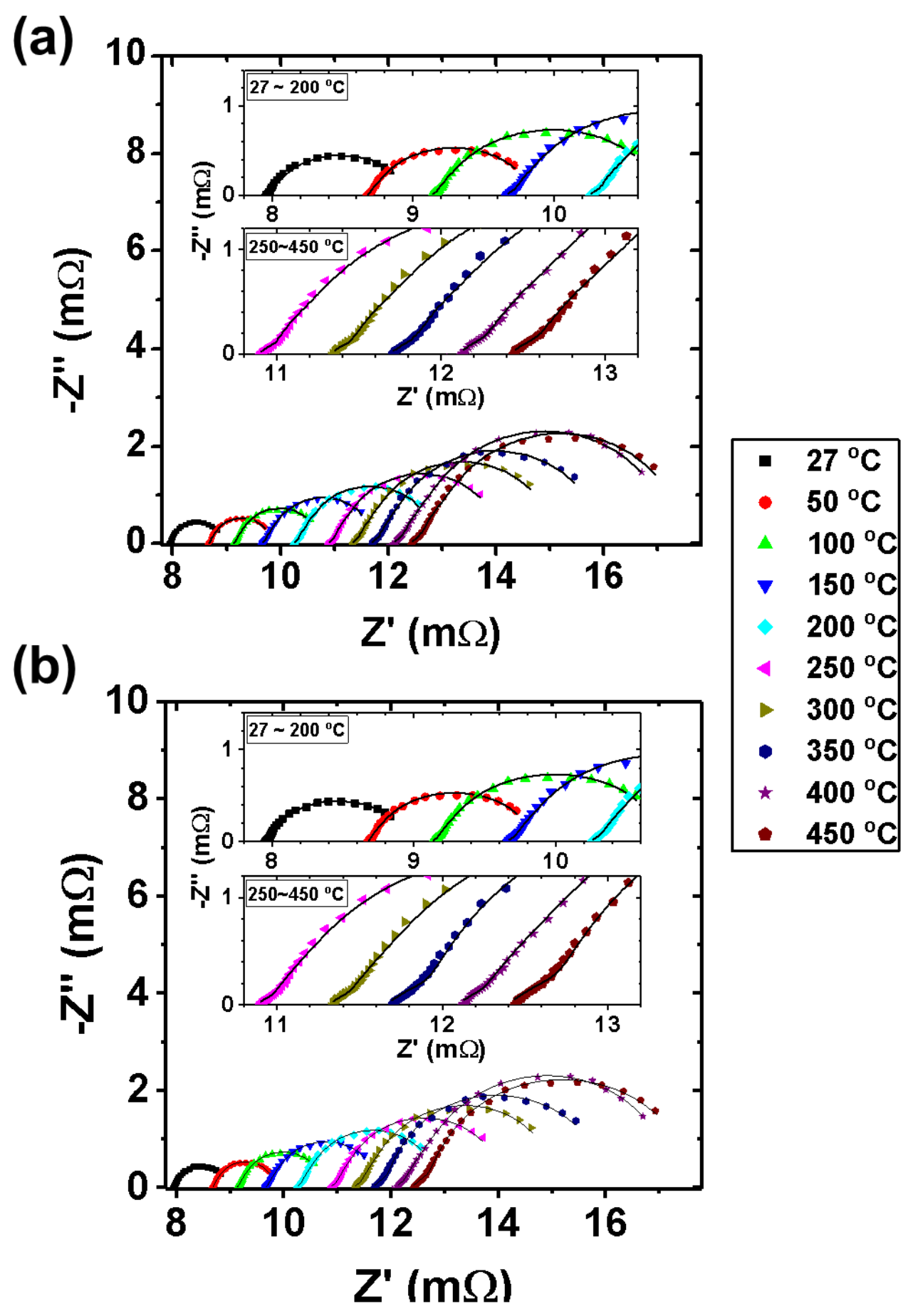

Fig. 5 Impedance spectra of the two-couple SKD device at various temperatures (filled symbols) and mathematical model fitting results (lines) using the (a) ideal and (b) comprehensive models. 
The obtained spectra were analyzed using both the ideal and the comprehensive models. Both models require five fitting parameters $\left(R_{\Omega}, R_{\mathrm{C}}, R_{\mathrm{TE}}, \omega_{\mathrm{C}}\right.$, and $\left.\omega_{\mathrm{TE}}\right)$ to describe the spectrum obtained at each temperature when the thermal conductivity of the $\mathrm{Al}_{2} \mathrm{O}_{3}$ plate $\left(\lambda_{\mathrm{C}}\right)$ is known at each temperature. Considerable care must be taken to use an appropriate value for $\lambda_{\mathrm{C}}$, as it is

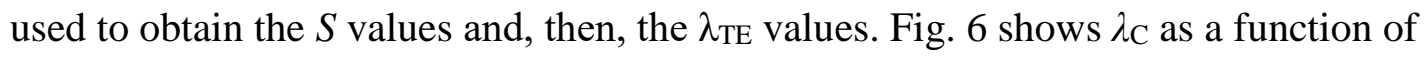
temperature, as determined using differential scanning calorimetry and laser flash analysis results. As shown in Fig. $6, \lambda_{\mathrm{C}}$ decreases by $50 \%$ with the increase in temperature; hence, it is necessary to measure the thermal conductivity of the insulating plate of the thermoelectric device to realize accurate determination of the thermoelectric properties from the impedance spectra of the two-couple SKD device. For the comprehensive model, the convective heat transfer coefficient $\left(h_{\mathrm{C}}\right)$ value at the external surface of the $\mathrm{Al}_{2} \mathrm{O}_{3}$ plate at each temperature is required. At room temperature, a minimum value of $25 \mathrm{~W} \cdot \mathrm{m}^{-2} \cdot \mathrm{K}^{-1}$ obtained a reasonable fitting between the experimental and simulated data, whereas the $R_{\mathrm{C}}$ values were overestimated when the $h_{\mathrm{C}}$ value was less than $25 \mathrm{~W} \cdot \mathrm{m}^{-2} \cdot \mathrm{K}^{-1}$. We explored varying the $h_{\mathrm{C}}$ values to investigate the effect of $h_{\mathrm{C}}$ on the $R_{\mathrm{C}}$ values. The $R_{\mathrm{C}}$ values were found to be within the error range given by nonlinear least-squares fitting analysis at other temperatures when $h_{\mathrm{C}}$ was within the range $25 \pm 15$ $\mathrm{W} \cdot \mathrm{m}^{-2} \cdot \mathrm{K}^{-1}$. It has been reported that typical heat transfer coefficient values for natural convection at ambient pressure are in the range of $2-25 \mathrm{~W} \cdot \mathrm{m}^{-2} \cdot \mathrm{K}^{-1}[54]$. The somewhat high heat transfer coefficient value at the external surface of the $\mathrm{Al}_{2} \mathrm{O}_{3}$ plate may possibly be explained by convective contributions from other parts of the SKD device. Even though the $h_{\mathrm{C}}$ value is somewhat higher than expected at this experimental pressure, the impact of $h_{\mathrm{C}}$ on the $Z T$ value of the device is insignificant (less than 6\%) [54] and within the fitting error in this study. Therefore, we used $25 \mathrm{~W} \cdot \mathrm{m}^{-2} \cdot \mathrm{K}^{-1}$ as the $h_{\mathrm{C}}$ value when performing the comprehensive model analysis. 


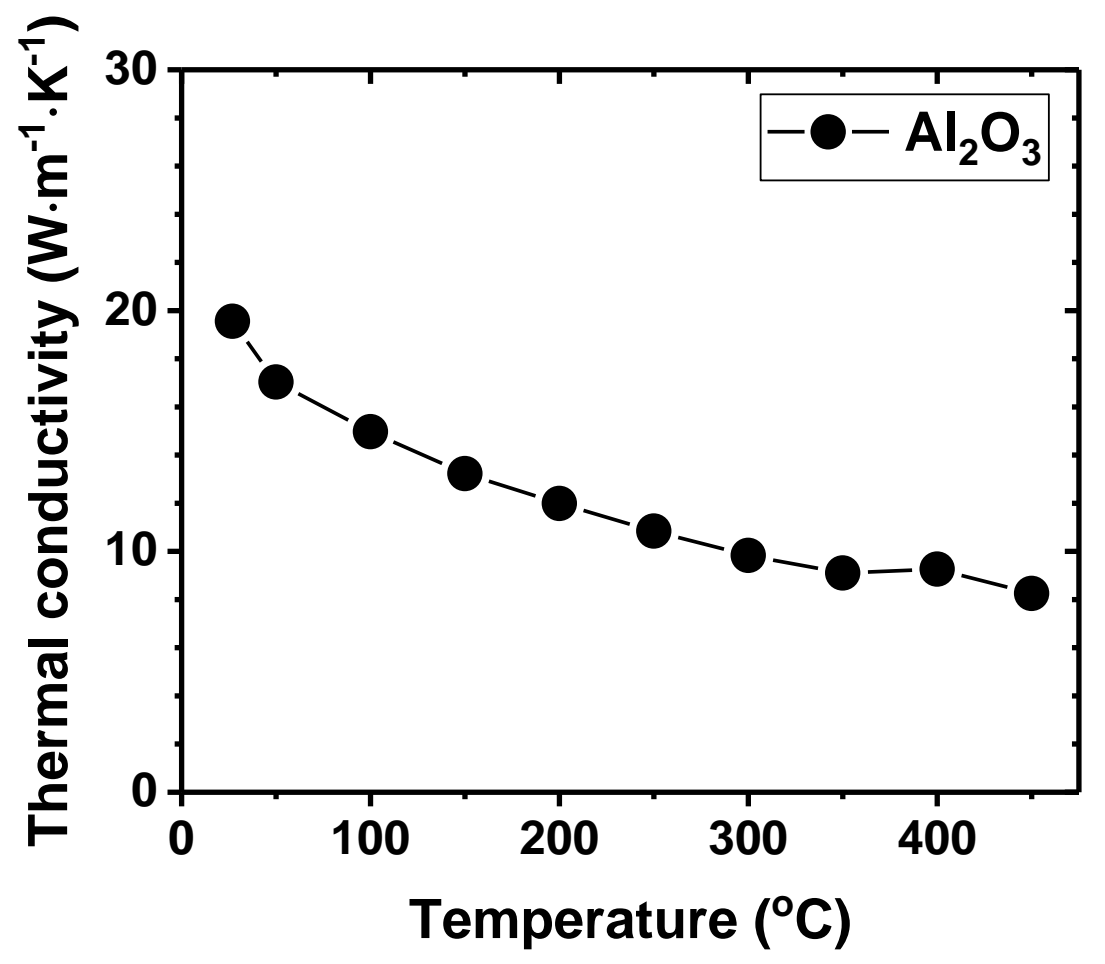

Fig. 6 Thermal conductivity of the $\mathrm{Al}_{2} \mathrm{O}_{3}$ insulating plate $(\lambda \mathrm{C})$ in the two-couple SKD device as a function of temperature. 
Fig. 7 shows the values obtained for the five fitting parameters $\left(R_{\Omega}, R_{\mathrm{C}}, R_{\mathrm{TE}}, \omega_{\mathrm{C}}\right.$, and $\left.\omega_{\mathrm{TE}}\right)$ as functions of temperature in the range $23-450{ }^{\circ} \mathrm{C}$. The error bars represent the computed standard error of each parameter obtained from the converged fitting procedure. All the resistances $\left(R_{\Omega}, R_{\mathrm{C}}\right.$, and $\left.R_{\mathrm{TE}}\right)$ increased with increasing temperature, whereas the angular frequencies $\left(\omega_{\mathrm{C}}\right.$ and $\left.\omega_{\mathrm{TE}}\right)$ were found to decrease. The increase in $R_{\Omega}$ is due to the increase in the overall ohmic resistance of the device, whereas the increase in $R_{\mathrm{TE}}$ is mainly due to the increase of the Seebeck voltage of the SKD thermoelectric materials. The angular frequencies, $\omega_{\mathrm{C}}$ and $\omega_{\mathrm{TE}}$, are directly proportional to the thermal diffusivity of the $\mathrm{Al}_{2} \mathrm{O}_{3}$ plate and $\mathrm{SKD}$ materials, respectively. The thermal diffusivity of the $\mathrm{Al}_{2} \mathrm{O}_{3}$ plate decreased by $\sim 30 \%$ with the increase in temperature, whereas that of SKD showed a negligible temperature dependence. Hence, the observed trends for $\omega_{\mathrm{C}}$ and $\omega_{\mathrm{TE}}$ reflect the thermal diffusivity trends of the $\mathrm{Al}_{2} \mathrm{O}_{3}$ plate and SKD materials. The most pronounced change was observed for the $R_{\mathrm{C}}$ value, which increased from $\sim 0.1 \mathrm{~m} \Omega$ at $23{ }^{\circ} \mathrm{C}$ to $\sim 1.5 \mathrm{~m} \Omega$ at $450{ }^{\circ} \mathrm{C}$. Using the comprehensive model, the $R_{\mathrm{C}}$ value at $450{ }^{\circ} \mathrm{C}$ was approximately 15 times greater than the value at $23{ }^{\circ} \mathrm{C}$; hence, the $R_{\mathrm{C}}$ of the $\mathrm{SKD}$ device contributes more than $20 \%$ of the overall electrical resistance of the device at $450{ }^{\circ} \mathrm{C}$, but less than $8 \%$ at $23{ }^{\circ} \mathrm{C}$. 
(a)
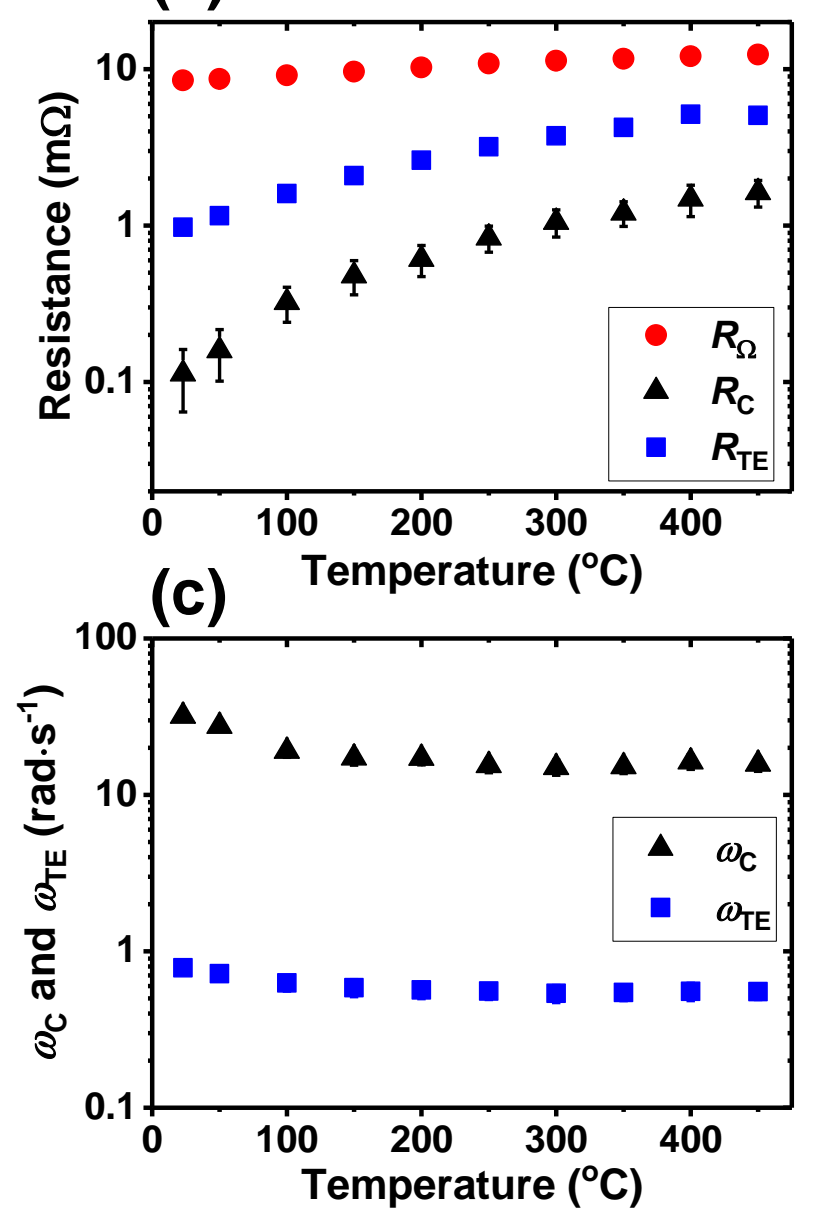

(b)
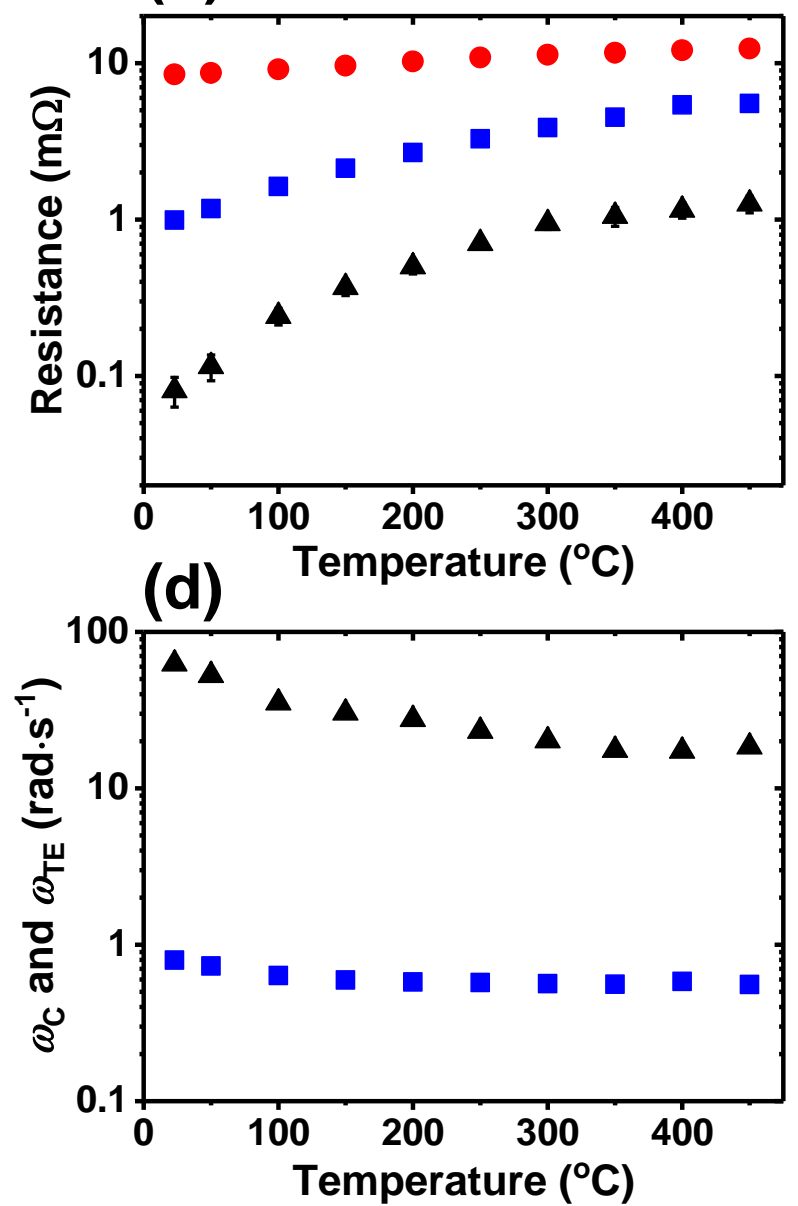

Fig. 7 Variations in the resistance $\left(R_{\Omega}, R_{\mathrm{C}}\right.$, and $\left.R_{\mathrm{TE}}\right)$ and angular frequency $\left(\omega_{\mathrm{C}}\right.$ and $\left.\omega_{\mathrm{TE}}\right)$ values extracted from the (a, c) ideal and (b, d) comprehensive models as functions of temperature. The error bars represent the standard errors of the complex nonlinear least-squares fitting; where bars are not shown, they are smaller than the symbol size. 
To assess the $\lambda_{\mathrm{TE}}, \sigma, S$, and $Z T$ values of the SKD device, the three resistances $\left(R_{\Omega}, R_{\mathrm{C}}\right.$, and $\left.R_{\mathrm{TE}}\right)$ must be accurately obtained from the fitting. As the fitting error of $R_{\Omega}$ is less than $0.1 \%$ of its fitted value, we have constructed error maps in the $R_{\mathrm{C}}$ and $R_{\mathrm{TE}}$ plane for the values obtained by fitting the impedance spectra at $150,250,350$, and $450{ }^{\circ} \mathrm{C}$ to the comprehensive model. The goodness-of-fit parameter $\chi^{2}$ was introduced to assess the quality of fitting: $\chi^{2}=\sum_{k=1}^{n}\left(\left(g_{k}-\right.\right.$ $\left.\left.g_{\mathrm{m}, k}\right) / g_{k}\right)$, where $g_{k}$ and $g_{\mathrm{m}, k}$ represent the experimental data obtained and the fitted values predicted by the model, respectively. $\chi^{2}$ values were calculated for a $100 \times 100$ grid around the fitted $R_{\mathrm{C}}$ and $R_{\mathrm{TE}}$ values to demonstrate the effect of both $R_{\mathrm{C}}$ and $R_{\mathrm{TE}}$ on $\chi^{2}$. Fig. 8 shows the error maps of the fitting results, confirming that an absolute maximum for reciprocal $\chi^{2}$ of greater than $500\left(\chi^{2} \leq 0.002\right)$ can be obtained for the fitted $R_{\mathrm{C}}$ and $R_{\mathrm{TE}}$ values, signifying the reliability of the fitting in this study. 

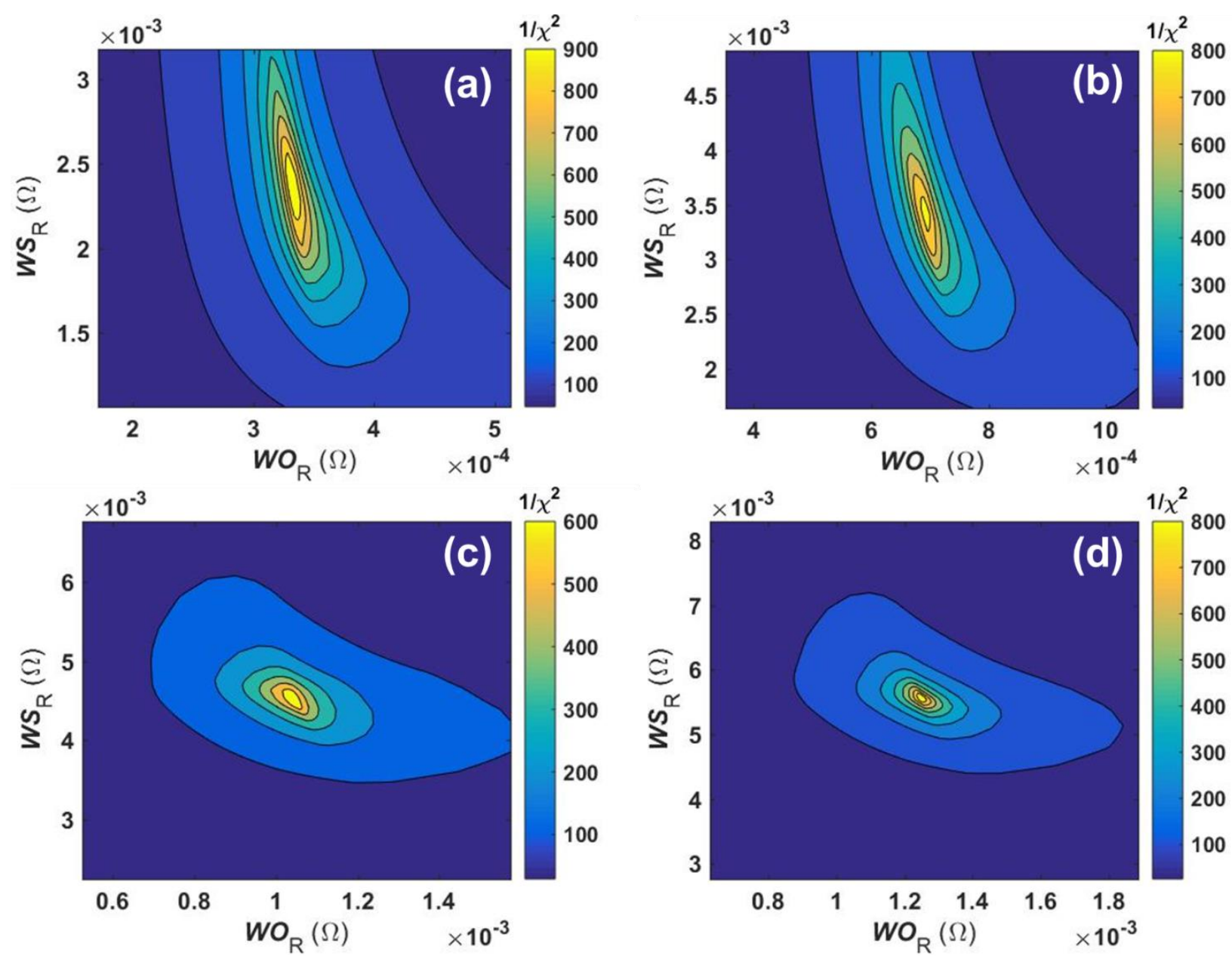

Fig. 8 Fitting error plots showing the values of reciprocal $\chi^{2}$ calculated for $100 \times 100$ grid around the fitted $R_{\mathrm{C}}$ and $R_{\mathrm{TE}}$ values. The highest value of $\chi^{-2}$ at the center of the plot indicates the lowest deviation of the fitted values from the values obtained at (a) $150{ }^{\circ} \mathrm{C}$, (b) $250{ }^{\circ} \mathrm{C}$, (c) $350{ }^{\circ} \mathrm{C}$, and (d) $450{ }^{\circ} \mathrm{C}$. 
Fig. 9 shows the $S, \lambda_{\mathrm{TE}}, \sigma$, and $Z T$ values of the SKD device as a function of temperature, as obtained from the impedance spectra using both the ideal and the comprehensive models. The values measured for p-type and n-type SKD materials using ZEM-3 (Ulvac-Riko) and laser flash analysis (LFA 457, Netzsch) [24] are also given for comparison. It can be seen that the $S$ and $\lambda_{\mathrm{TE}}$ values from the comprehensive model show better agreement than those from the ideal model, whereas the $\sigma$ and $Z T$ values from both models are similar. Therefore, it can be concluded that a model that considers thermal convection, radiation, and spreading-constriction thermal impedance corrections will afford more accurate estimations of $S$ and $\lambda_{\mathrm{TE}}$ than the adiabatic ideal model. It was found that $\sigma$ decreases with increasing temperature, whereas $S$ increases with increasing temperature. $\lambda_{\mathrm{TE}}$ increases until $300^{\circ} \mathrm{C}$, and then tends to decrease until $450{ }^{\circ} \mathrm{C}$. The $\sigma$ values obtained for the SKD device are approximately $20 \%$ lower than average values for p-type and n-type SKD materials owing to the presence of parasitic electrical resistances between the electrical contacts and SKD and the resistance of the electrical connection wires. The obtained $S$ values for the SKD device are 8-20\% higher than the average values for p-type and n-type SKD materials from both the ideal and the comprehensive models. However, the average power factor $\left(S^{2} \sigma\right)$ values of the SKD device only deviate by $7 \%$ and $17 \%$ in comparison with the average values of p-type and n-type SKD materials from the comprehensive and the ideal models, respectively. The $\lambda_{\mathrm{TE}}$ values obtained for the SKD device are $50 \%$ and $100 \%$ higher than those of p-type and n-type SKD materials from the comprehensive and the ideal models, respectively; hence, the somewhat low $Z T$ values of the SKD device (60\% of the average value for $\mathrm{p}$ - and ntype $\mathrm{SKD}$ ) in this study could be due to the high thermal conductivity values from the impedance spectra. This observation may be associated with variations in the thermoelectric properties of the SKD thermoelectric legs during device fabrication. It is necessary to conduct further studies 
to verify the differences between the thermoelectric properties of devices and materials and understand the underlying fundamental properties of thermoelectric devices. 

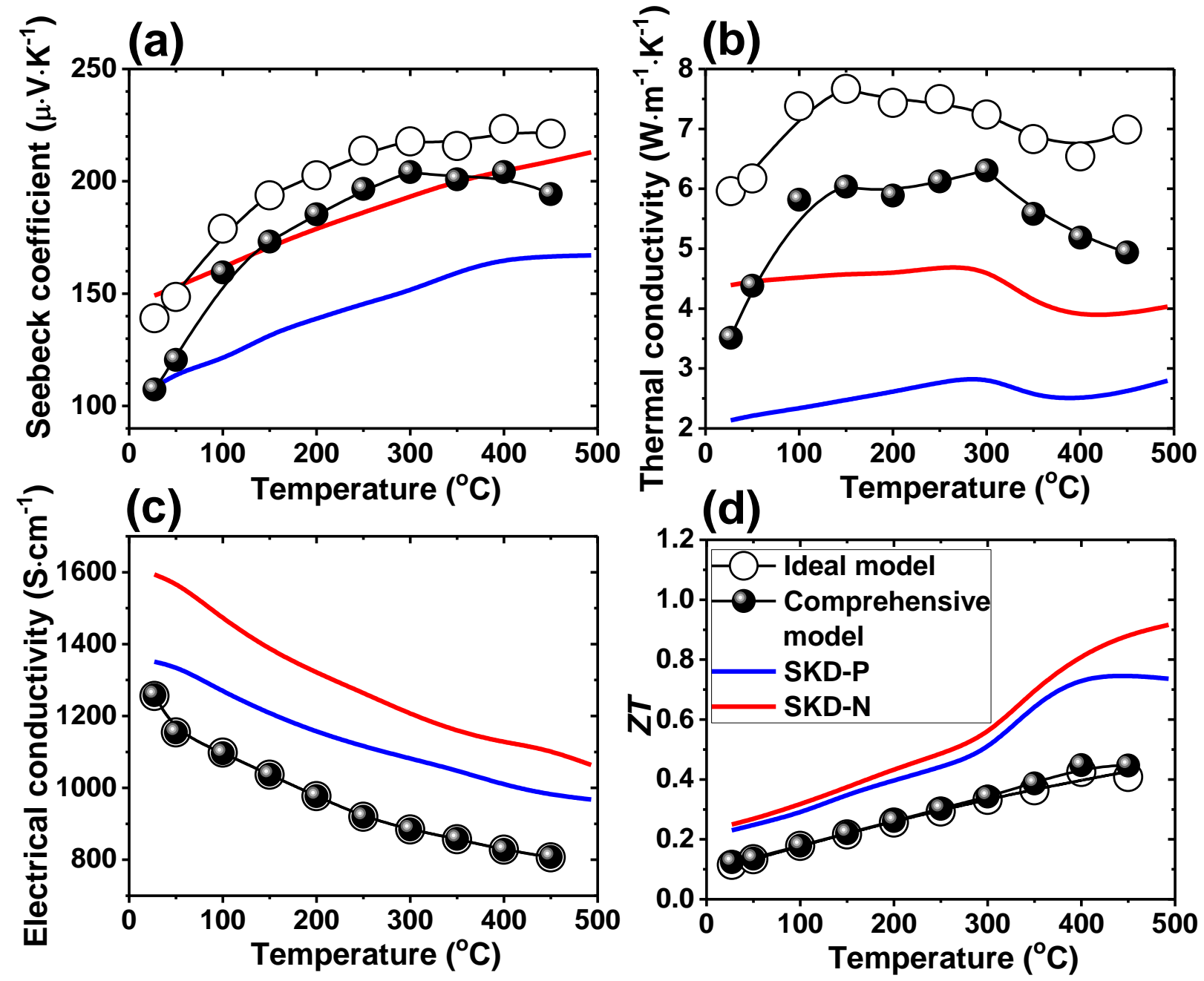

Fig. 9 Variations in (a) electrical conductivity $(\sigma)$, (b) thermal conductivity $\left(\lambda_{\mathrm{TE}}\right)$, (c) Seebeck coefficient $(S)$, and (d) figure of merit $(Z T)$ of the two-couple SKD device as a function of temperature, as determined from the impedance spectra by employing the ideal and comprehensive models. For comparison, the properties of SKD materials, measured using ZEM3 (Ulvac-Riko) and laser flash analysis (LFA 457, Netzsch) [24], are also displayed. 


\section{Conclusions}

We have systematically investigated the thermoelectric properties of a skutterudite-based thermoelectric device using impedance spectroscopy in the temperature range $23-450{ }^{\circ} \mathrm{C}$. Prior to the impedance spectroscopy measurements, the interface from the titanium metallized skutterudite joints was characterized by combining scanning and transmission electron microscopy with specific electrical contact resistance measurements. Intermetallic phases (titanium antimony and titanium cobalt antimony compounds), found at the interface between titanium and skutterudite owing to the interdiffusion of titanium and skutterudite during the spark plasma sintering process, exhibited a low specific contact resistance of $3-4.5 \mu \Omega \cdot \mathrm{cm}^{2}$. All impedance spectra of the skutterudite-based thermoelectric device were Kramers-Kronigtransformable, which enabled least-squares analysis using both the ideal and the comprehensive mathematical models. Both models were used to extract the figure of merit and three key parameters (Seebeck coefficient, thermal conductivity, and electrical conductivity) from the impedance spectra as a function of temperature. Both models yielded similar electrical conductivity and figure of merit values, whereas the comprehensive model estimated the Seebeck coefficients and thermal conductivity values more accurately than the ideal model. The figure of merit values for the skutterudite-based device were $60 \%$ lower than those of skutterudite materials, mainly because the thermal conductivity of the device was higher than that of the skutterudite materials, whereas the average power factor values of the device were close to those of the materials. These deviations may be associated with variations in the thermoelectric properties of the skutterudite thermoelectric legs during device fabrication. These encouraging results indicate that the impedance spectroscopy is a useful tool for investigating the properties of thermoelectric devices. Furthermore, this study provides an important opportunity 
to advance the understanding of thermoelectric device property, which is valuable information for the design and optimization of thermoelectric conversion system to achieve the best performance for the real applications.

\section{Acknowledgements}

This work was supported by the Korea Institute of Energy Technology Evaluation and Planning (KETEP) and the Ministry of Trade, Industry \& Energy (MOTIE) of the Republic of Korea (No. 20172010000830). Juyeon Hwang (Chungnam National University) is gratefully acknowledged for preparation of the SKD-based device.

Declarations of interest: none

\section{Glossary \\ DD, didymium}

EDS, energy-dispersive X-ray spectroscopy

FIB, focused ion beam

KK, Kramers-Kronig

HAADF-STEM, high-angle annular dark-field scanning transmission electron microscopy

Mm, mischmetal 
SAED, selected-area electron diffraction

SEM, scanning electron microscopy

SKD, skutterudite

SPS, spark plasma sintering

$A$, area of the thermoelectric legs

$C_{\mathrm{p}}$, specific heat

$D$, thermal diffusivity

$h_{1}$, radiative heat loss of the thermoelectric legs

$h_{2}$, radiative heat loss at the internal surface of the $\mathrm{Al}_{2} \mathrm{O}_{3}$ plate

$h_{3}$, radiative and convective heat loss at the external surface of the $\mathrm{Al}_{2} \mathrm{O}_{3}$ plate

$h_{\mathrm{C}}$, convective heat transfer coefficient at the external surface of the ceramic plate

I, current amplitude

$J_{0}$, zero-order Bessel function

$J_{1}$, first-order Bessel function

$L$, length of the thermoelectric element

$L_{\mathrm{C}}$, length of the ceramic plate

$N$, number of thermoelectric couples

$P P$, Peltier power density 
$R_{\mathrm{C}}$, thermoelectric resistance induced by the ceramic layer

$R_{\mathrm{TE}}$, thermoelectric resistance

$R_{\Omega}$, ohmic resistance

$r_{0}$, thermoelectric leg radius

$S$, Seebeck coefficient

$S_{\text {ave, average Seebeck coefficient }}$

$T$, absolute temperature

$Y_{\mathrm{SC}}$, spreading-constriction impedance

$Z_{\mathrm{im}}$, imaginary part of the impedance

$Z_{\text {re, }}$ real part of the impedance

$Z_{\mathrm{Wa}}$, adiabatic Warburg element

$Z_{\mathrm{WCT}}$, constant temperature Warburg element

$Z T$, figure of merit

$\alpha_{\mathrm{TE}}$, thermal diffusivity of the thermoelectric element

$\alpha_{\mathrm{C}}$, thermal diffusivity of the ceramic plate

$\varepsilon$, emissivity

$\lambda$, thermal conductivity

$\lambda_{\mathrm{C}}$, thermal conductivity of the insulating ceramic plate 
$\lambda_{\mathrm{TE}}$, thermal conductivity of the thermoelectric element

$\eta$, filling factor

$\rho$, mass density

$\sigma$, electrical conductivity

$\sigma_{\mathrm{B}}$, Stefan-Boltzmann constant

$\chi^{2}$, goodness-of-fit parameter

$\omega$, angular frequency

$\omega_{C}$, characteristic angular frequency of thermal diffusion of ceramic materials

$\omega_{\mathrm{TE}}$, characteristic angular frequency of thermal diffusion of thermoelectric materials 


\section{References}

[1] Meroz O, Gelbstein Y. Thermoelectric $\mathrm{Bi}_{2} \mathrm{Te}_{3-\mathrm{x}} \mathrm{Se}_{\mathrm{x}}$ alloys for efficient thermal to electrical energy conversion. Phys Chem Chem Phys 2018;20:4092-9. doi:10.1039/C7CP06176E.

[2] Beeri O, Rotem O, Hazan E, Katz EA, Braun A, Gelbstein Y. Hybrid photovoltaicthermoelectric system for concentrated solar energy conversion: Experimental realization and modeling. J Appl Phys 2015;118:115104. doi:10.1063/1.4931428.

[3] Vizel R, Bargig T, Beeri O, Gelbstein Y. Bonding of $\mathrm{Bi}_{2} \mathrm{Te}_{3}$-Based Thermoelectric Legs to Metallic Contacts Using Bi ${ }_{0.82} \mathrm{Sb}_{0.18}$ Alloy. J Electron Mater 2016;45:1296-300. doi:10.1007/s11664-015-4003-2.

[4] Guttmann GM, Gertner R, Samuha S, Ben-Ayoun D, Haroush S, Gelbstein Y. Thermoelectric and mechanical properties of $\mathrm{Ag}$ and $\mathrm{Cu}$ doped $(\mathrm{GeTe})_{0.96}\left(\mathrm{Bi}_{2} \mathrm{Te}_{3}\right)_{0.04}$. MRS Commun 2018;8:1292-9. doi:10.1557/mrc.2018.150.

[5] Hazan E, Madar N, Parag M, Casian V, Ben-Yehuda O, Gelbstein Y. Effective Electronic Mechanisms for Optimizing the Thermoelectric Properties of GeTe-Rich Alloys. Adv Electron Mater 2015;1:1500228. doi:10.1002/aelm.201500228.

[6] Gelbstein Y, Dashevsky Z, Dariel MP. Highly efficient bismuth telluride doped p-type $\mathrm{Pb}_{0.13} \mathrm{Ge}_{0.87} \mathrm{Te}$ for thermoelectric applications. Phys Status Solidi - Rapid Res Lett 2007;1:232-4. doi:10.1002/pssr.200701160.

[7] Wang H, Hwang J, Snedaker ML, Kim I, Kang C, Kim J, Stucky GD, Bowers J, Kim W. High Thermoelectric Performance of a Heterogeneous PbTe Nanocomposite. Chem Mater 
2015;27:944-9. doi:10.1021/cm5042138.

[8] Sootsman JR, Chung DY, Kanatzidis MG. New and Old Concepts in Thermoelectric Materials. Angew Chemie Int Ed 2009;48:8616-39. doi:10.1002/anie.200900598.

[9] Fitriani, Ovik R, Long BD, Barma MC, Riaz M, Sabri MFM, Said S, Saidur R. A review on nanostructures of high-temperature thermoelectric materials for waste heat recovery. Renew Sustain Energy Rev 2016;64:635-59. doi:10.1016/J.RSER.2016.06.035.

[10] Gayner C, Kar KK. Recent advances in thermoelectric materials. Prog Mater Sci 2016;83:330-82. doi:10.1016/J.PMATSCI.2016.07.002.

[11] Zhu T, Liu Y, Fu C, Heremans JP, Snyder JG, Zhao X. Compromise and Synergy in HighEfficiency Thermoelectric Materials. Adv Mater 2017;29:1605884. doi:10.1002/adma.201605884.

[12] Rogl G, Rogl P. Skutterudites, a most promising group of thermoelectric materials. Curr Opin Green Sustain Chem 2017;4:50-7. doi:10.1016/J.COGSC.2017.02.006.

[13] Appel O, Schwall M, Mogilyansky D, Köhne M, Balke B, Gelbstein Y. Effects of Microstructural Evolution on the Thermoelectric Properties of Spark-Plasma-Sintered $\mathrm{Ti}_{0.3} \mathrm{Zr}_{0.35} \mathrm{Hf}_{0.35} \mathrm{NiSn}$ Half-Heusler Compound. J Electron Mater 2013;42:1340-5. doi:10.1007/s11664-012-2249-5.

[14] He J, Tritt TM. Advances in thermoelectric materials research: Looking back and moving forward. Science 2017;357:eaak9997. doi:10.1126/science.aak9997.

[15] Appel O, Zilber T, Kalabukhov S, Beeri O, Gelbstein Y. Morphological effects on the thermoelectric properties of $\mathrm{Ti}_{0.3} \mathrm{Zr}_{0.35} \mathrm{Hf}_{0.35} \mathrm{Ni}_{1+\delta} \mathrm{Sn}$ alloys following phase separation. $\mathrm{J}$ 
Mater Chem C 2015;3:11653-9. doi:10.1039/C5TC03214H.

[16] Wang H, McCarty R, Salvador JR, Yamamoto A, König J. Determination of Thermoelectric Module Efficiency: A Survey. J Electron Mater 2014;43:2274-86. doi:10.1007/s11664-014-3044-2.

[17] Kato K, Hatasako Y, Kashiwagi M, Hagino H, Adachi C, Miyazaki K. Fabrication of a Flexible Bismuth Telluride Power Generation Module Using Microporous Polyimide Films as Substrates. J Electron Mater 2014;43:1733-9. doi:10.1007/s11664-013-2852-0.

[18] Hu X, Jood P, Ohta M, Kunii M, Nagase K, Nishiate H, Kanazidis MG, Yamamoto A. Power generation from nanostructured PbTe-based thermoelectrics: comprehensive development from materials to modules. Energy Environ Sci 2016;9:517-29. doi:10.1039/C5EE02979A.

[19] Jood P, Ohta M, Yamamoto A, Kanatzidis MG. Excessively Doped PbTe with GeInduced Nanostructures Enables High-Efficiency Thermoelectric Modules. Joule 2018;2:1339-55. doi:10.1016/J.JOULE.2018.04.025.

[20] Nie G, Suzuki S, Tomida T, Sumiyoshi A, Ochi T, Mukaiyama K, Kikuchi M, Guo JQ, Yamamoto A, Obara H. Performance of Skutterudite-Based Modules. J Electron Mater 2017;46:2640-4. doi:10.1007/s11664-016-4849-y.

[21] Zhao D, Tian C, Tang S, Liu Y, Jiang L, Chen L. Fabrication of a CoSb3-based thermoelectric module. Mater Sci Semicond Process 2010;13:221-4. doi:10.1016/J.MSSP.2010.10.016.

[22] Guo JQ, Geng HY, Ochi T, Suzuki S, Kikuchi M, Yamaguchi Y, ITO S. Development of 
Skutterudite Thermoelectric Materials and Modules. J Electron Mater 2012;41:1036-42. doi:10.1007/s11664-012-1958-0.

[23] Salvador JR, Cho JY, Ye Z, Moczygemba JE, Thompson AJ, Sharp JW, Koenig JD, Maloney R, Thompson T, Sakamoto J, Wang H, Wereszczak AA. Conversion efficiency of skutterudite-based thermoelectric modules. Phys Chem Chem Phys 2014;16:12510-20. doi:10.1039/C4CP01582G.

[24] Park SH, Jin Y, Cha J, Hong K, Kim Y, Yoon H, Yoo CY, Chung I. High-Power-Density Skutterudite-Based Thermoelectric Modules with Ultralow Contact Resistivity Using FeNi Metallization Layers. ACS Appl Energy Mater 2018;1:1603-11. doi:10.1021/acsaem.8b00064.

[25] Zhang Q, Zhou Z, Dylla M, Agne MT, Pei Y, Wang L, Tang Y, Liao J, Li J, Bai S, Jiang W, Chen L, Snyder GJ. Realizing high-performance thermoelectric power generation through grain boundary engineering of skutterudite-based nanocomposites. Nano Energy 2017;41:501-10. doi:https://doi.org/10.1016/j.nanoen.2017.10.003.

[26] Bartholomé K, Balke B, Zuckermann D, Köhne M, Müller M, Tarantik K, König J. Thermoelectric Modules Based on Half-Heusler Materials Produced in Large Quantities. J Electron Mater 2014;43:1775-81. doi:10.1007/s11664-013-2863-x.

[27] Populoh S, Brunko O, Gałązka K, Xie W, Weidenkaff A. Half-Heusler (TiZrHf)NiSn Unileg Module with High Powder Density. Materials (Basel) 2013;6:1326-32. doi:10.3390/ma6041326.

[28] Fu C, Bai S, Liu Y, Tang Y, Chen L, Zhao X, Zhu T. Realizing high figure of merit in 
heavy-band p-type half-Heusler thermoelectric materials. Nat Commun 2015;6:8144. doi:10.1038/ncomms9144.

[29] García-Cañadas J, Min G. Impedance spectroscopy models for the complete characterization of thermoelectric materials. J Appl Phys 2014;116:174510. doi:10.1063/1.4901213.

[30] Beltrán-Pitarch B, Prado-Gonjal J, Powell A V, Ziolkowski P, García-Cañadas J. Thermal conductivity, electrical resistivity, and dimensionless figure of merit (ZT) determination of thermoelectric materials by impedance spectroscopy up to $250{ }^{\circ} \mathrm{C}$. J Appl Phys 2018;124:25105. doi:10.1063/1.5036937.

[31] Beltrán-Pitarch B, Prado-Gonjal J, Powell A V., García-Cañadas J. Experimental conditions required for accurate measurements of electrical resistivity, thermal conductivity, and dimensionless figure of merit ( $Z T$ ) using Harman and impedance spectroscopy methods. J Appl Phys 2019;125:025111. doi:10.1063/1.5077071.

[32] García-Cañadas J, Min G. Low Frequency Impedance Spectroscopy Analysis of Thermoelectric Modules. J Electron Mater 2014;43:2411-4. doi:10.1007/s11664-0143095-4.

[33] Yoo C-Y, Kim Y, Hwang J, Yoon H, Cho BJ, Min G, Park SH. Impedance spectroscopy for assessment of thermoelectric module properties under a practical operating temperature. Energy 2018;152:834-9. doi:10.1016/J.ENERGY.2017.12.014.

[34] Beltrán-Pitarch B, Márquez-García L, Min G, García-Cañadas J. Measurement of thermal conductivity and thermal diffusivity using a thermoelectric module. Meas Sci Technol 
2017;28:045902. doi:10.1088/1361-6501/aa5c30.

[35] Otsuka M, Hasegawa Y, Arisaka T, Shinozaki R, Morita H. Dimensionless figure of merit and its efficiency estimation for transient response of thermoelectric module based on impedance spectroscopy. Appl Phys Express 2017;10:115801.

doi:10.7567/APEX.10.115801.

[36] Hasegawa Y, Otsuka M. Temperature dependence of dimensionless figure of merit of a thermoelectric module estimated by impedance spectroscopy. AIP Adv 2018;8:075222. doi:10.1063/1.5040181.

[37] Mesalam R, Williams HR, Ambrosi RM, García-Cañadas J, Stephenson K. Towards a comprehensive model for characterising and assessing thermoelectric modules by impedance spectroscopy. Appl Energy 2018;226:1208-18.

doi:10.1016/J.APENERGY.2018.05.041.

[38] Thiébaut E, Pesty F, Goupil C, Guegan G, Lecoeur P. Non-linear impedance spectroscopy for complete thermoelectric characterization: Beyond the zT estimation. J Appl Phys 2018;124:235106. doi:10.1063/1.5063419.

[39] Prado-Gonjal J, Phillips M, Vaqueiro P, Min G, Powell A V. Skutterudite Thermoelectric Modules with High Volume-Power-Density: Scalability and Reproducibility. ACS Appl Energy Mater 2018;1:6609-18. doi:10.1021/acsaem.8b01548.

[40] Yoo C-Y, Yoon H, Park SH. Direct Comparison of Thermoelectric Devices Using Impedance Spectroscopy. J Electron Mater 2018:1-7. doi:10.1007/s11664-018-6777-5.

[41] Rogl G, Grytsiv A, Failamani F, Hochenhofer M, Bauer E, Rogl P. Attempts to further 
enhance ZT in skutterudites via nano-composites. J Alloys Compd 2017;695:682-96. doi:https://doi.org/10.1016/j.jallcom.2016.10.114.

[42] Klinger M, IUCr. More features, more tools, more CrysTBox. J Appl Crystallogr 2017;50:1226-34. doi:10.1107/S1600576717006793.

[43] Kim Y, Yoon G, Park SH. Direct Contact Resistance Evaluation of Thermoelectric Legs. Exp Mech 2016;56:861-9. doi:10.1007/s11340-016-0131-8.

[44] Chen YQ. High-pressure synthesis and thermoelectric properties of Yb-filled skutterudite compounds. Muroran Institute of Technology, 2016.

[45] Zhao D, Li X, He L, Jiang W, Chen L. High temperature reliability evaluation of $\mathrm{CoSb}_{3} /$ electrode thermoelectric joints. Intermetallics 2009;17:136-41. doi:10.1016/j.intermet.2008.10.010.

[46] Fan J, Chen L, Bai S, Shi X. Joining of Mo to $\mathrm{CoSb}_{3}$ by spark plasma sintering by inserting a Ti interlayer. vol. 58. 2004. doi:10.1016/j.matlet.2004.07.041.

[47] Zhao D, Geng H, Chen L. Microstructure Contact Studies for Skutterudite Thermoelectric Devices. Int J Appl Ceram Technol 2012;9:733-41. doi:10.1111/j.17447402.2011.02703.x.

[48] Gu M, Xia X, Li X, Huang X, Chen L. Microstructural evolution of the interfacial layer in the $\mathrm{Ti}-\mathrm{Al} / \mathrm{Yb}_{0.6} \mathrm{Co}_{4} \mathrm{Sb}_{12}$ thermoelectric joints at high temperature. J Alloys Compd 2014;610:665-70. doi:10.1016/j.jallcom.2014.05.087.

[49] Gu M, Xia X, Huang X, Bai S, Li X, Chen L. Study on the interfacial stability of p-type $\mathrm{Ti} / \mathrm{Ce}_{\mathrm{y}} \mathrm{Fe}_{\mathrm{x}} \mathrm{Co}_{4-\mathrm{x}} \mathrm{Sb}_{12}$ thermoelectric joints at high temperature. J Alloys Compd 
2016;671:238-44. doi:10.1016/j.jallcom.2016.02.041.

[50] Zhao D, Geng H, Chen L. Microstructure Contact Studies for Skutterudite Thermoelectric Devices. Int J Appl Ceram Technol 2012;9:733-41. doi:10.1111/j.17447402.2011.02703.x.

[51] Boukamp BA. A Linear Kronig-Kramers Transform Test for Immittance Data Validation. J Electrochem Soc 1995;142:1885. doi:10.1149/1.2044210.

[52] Boukamp BA. Electrochemical impedance spectroscopy in solid state ionics: recent advances. Solid State Ionics 2004;169:65-73. doi:10.1016/J.SSI.2003.07.002.

[53] Hirschorn B, Orazem ME. On the Sensitivity of the Kramers-Kronig Relations to Nonlinear Effects in Impedance Measurements. J Electrochem Soc 2009;156:C345. doi:10.1149/1.3190160.

[54] Beltrán-Pitarch B, García-Cañadas J. Influence of convection at outer ceramic surfaces on the characterization of thermoelectric modules by impedance spectroscopy. J Appl Phys 2018;123:084505. doi:10.1063/1.5019881. 


\title{
Supplementary Material
}

\section{Determination of the thermoelectric properties of a skutterudite-based device at practical operating temperatures by impedance spectroscopy}

\author{
Chung-Yul Yoo,"*, Changho Yeon a, Younghwan Jin ${ }^{\mathrm{a}}$, Yeongseon Kim ${ }^{\mathrm{a}}$, Jinseop Songa ${ }^{\mathrm{a}}$ Hana Yoon ${ }^{\mathrm{a}}$, \\ Sang Hyun Park ${ }^{a}$, Braulio Beltrán-Pitarch ${ }^{\text {b }}$,Jorge García-Cañadas ${ }^{\text {b }}$ Gao Min ${ }^{\mathrm{c}}$
}

\begin{abstract}
${ }^{a}$ Korea Institute of Energy Research, 152 Gajeong-ro, Yuseong-gu, Daejeon 34129, Republic of Korea
${ }^{b}$ Department of Industrial Systems Engineering and Design, Universitat Jaume I, Campus del Riu Sec, 12071 Castellón, Spain
\end{abstract}

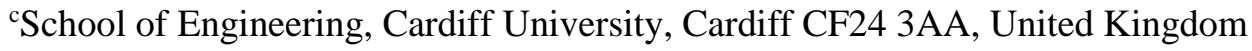




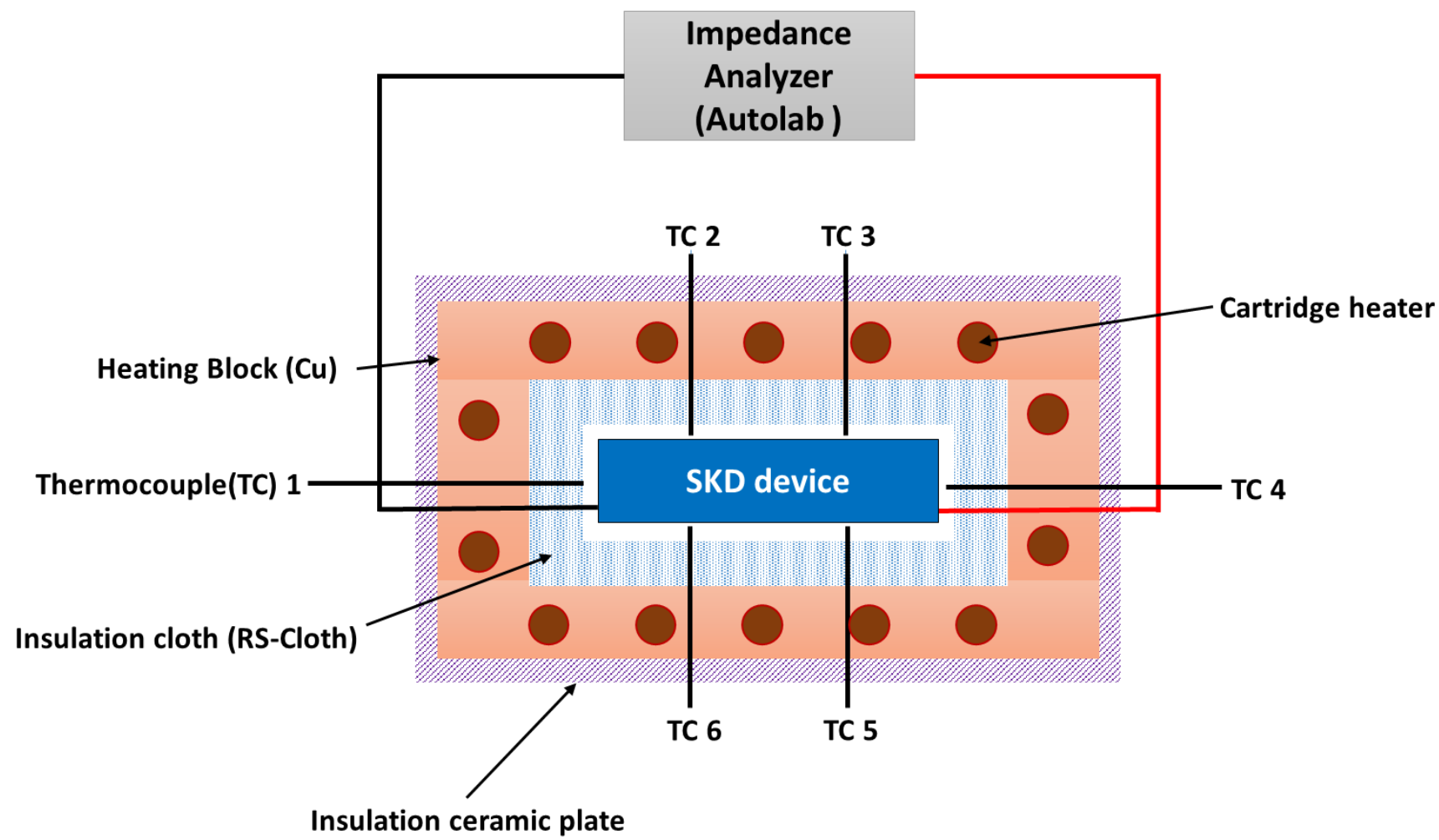

Fig. S1 Schematic of experimental setup (side view). 

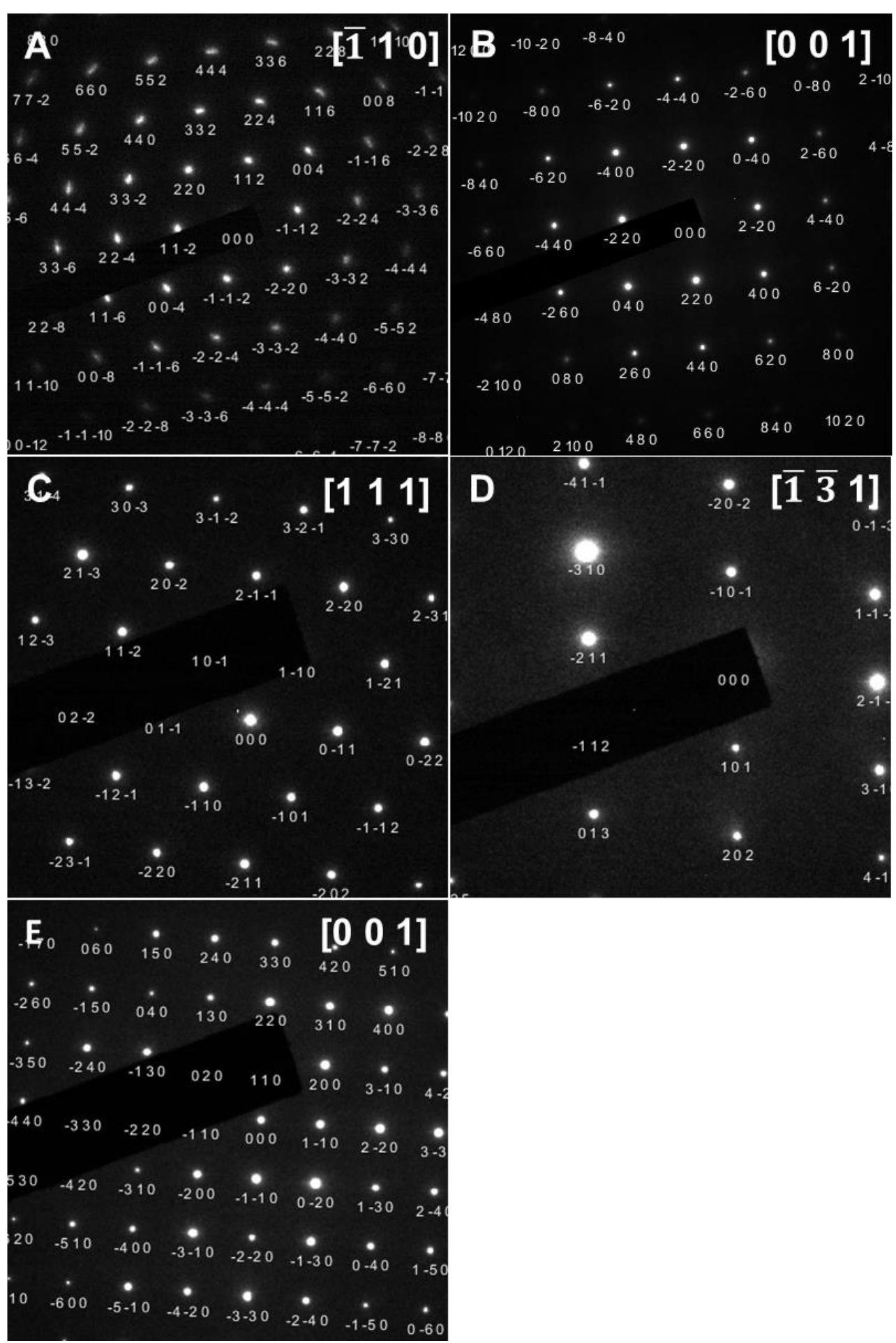

Fig. S2 Indexing of the selected-area electron diffraction (SAED) patterns at the Ti/SKD interface for p-type SKD. 


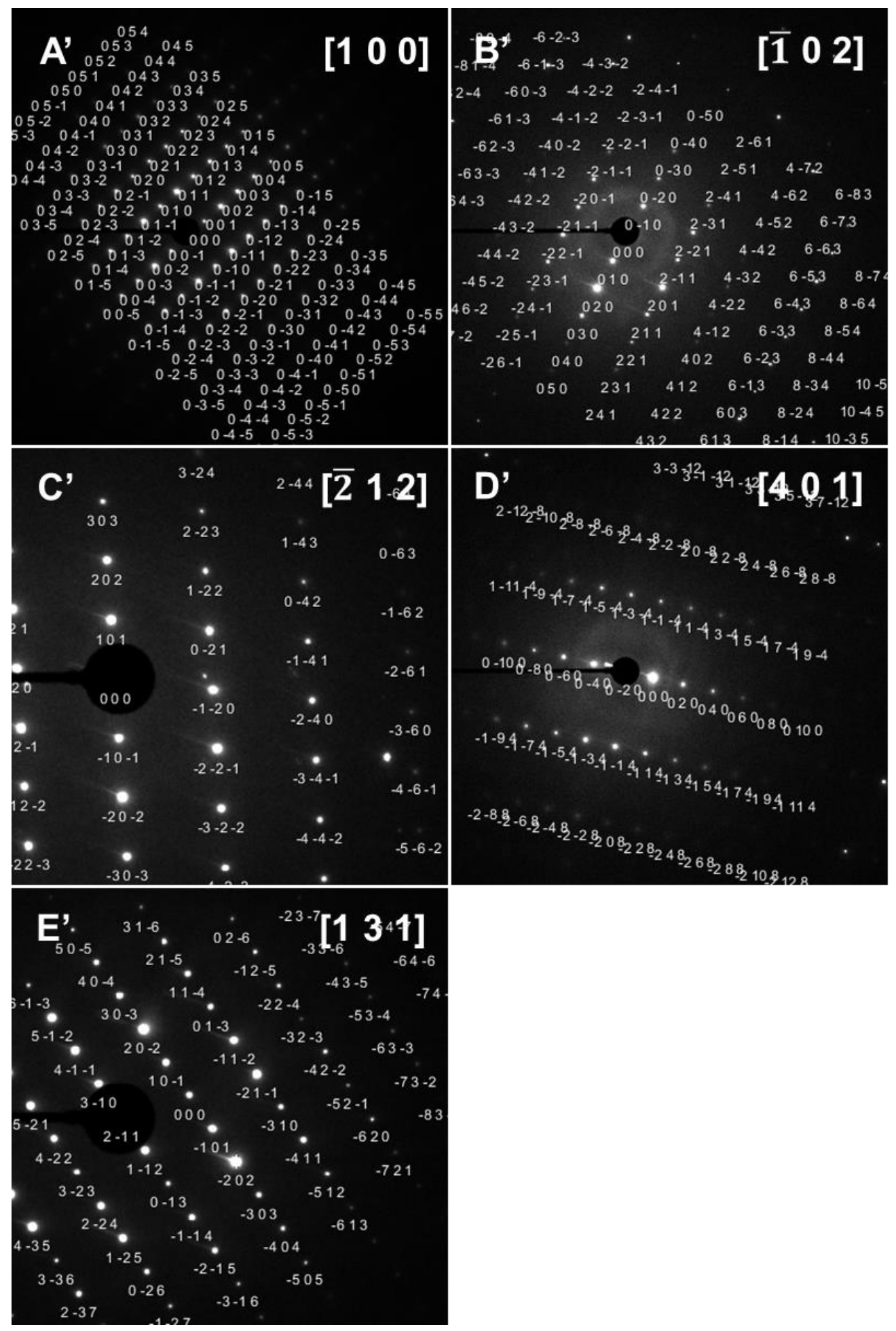

Fig. S3 Indexing of the selected-area electron diffraction (SAED) patterns at the Ti/SKD interface for n-type SKD. 